Annales Geophysicae (2003) 21: 539-558 C European Geosciences Union 2003

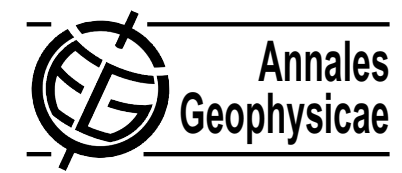

\title{
Multi-site observations of the association between aurora and plasma convection in the cusp/polar cap during a southeastward $\left(B_{y} \simeq\left|B_{z}\right|\right)$ IMF orientation
}

\author{
P. E. Sandholt ${ }^{1}$, J. Moen ${ }^{1}$, C. J. Farrugia ${ }^{2}$, S. W. H. Cowley ${ }^{3}$, M. Lester ${ }^{3}$, S. E. Milan ${ }^{3}$, C. Valladares ${ }^{4}$, W. F. Denig ${ }^{5}$, \\ and S. Eriksson ${ }^{6}$ \\ ${ }^{1}$ Department of Physics, University of Oslo, Oslo, Norway \\ ${ }^{2}$ Space Science Center, University of New Hampshire, Durham, UK \\ ${ }^{3}$ Department of Physics and Astronomy, University of Leicester, UK \\ ${ }^{4}$ Institute for Scientific Research, Boston College, Newton Center, Mass., USA \\ ${ }^{5}$ Space Vehicles Directorate, Air Force Research Laboratory, Hanscom AFB, Mass., USA \\ ${ }^{6}$ Laboratory for Atmospheric and Space Physics, University of Colorado, Boulder, USA
}

Received: 28 February 2002 - Revised: 12 July 2002 - Accepted: 16 July 2002

\begin{abstract}
In a case study we demonstrate the spatiotemporal structure of aurora and plasma convection in the cusp/polar cap when the interplanetary magnetic field (IMF) $B_{z}<0$ and $B_{y} \simeq\left|B_{z}\right|$ (clock angle in GSM $Y-Z$ plane: $\simeq$ $135^{\circ}$ ). This IMF orientation elicited a response different from that corresponding to strongly northward and southward IMF. Our study of this "intermediate state" is based on a combination of ground observations of optical auroral emissions and ionospheric plasma convection. Utilizing allsky cameras at Ny Ålesund, Svalbard and Heiss Island (Russian arctic), we are able to monitor the high-latitude auroral activity within the $\sim 10: 00-15: 00$ MLT sector. Information on plasma convection is obtained from the SuperDARN radars, with emphasis placed on line of sight observations from the radar situated in Hankasalmi, Finland (Cutlass). A central feature of the auroral observations in the cusp/polar cap region is a $\sim 30$-min long sequence of four brightening events, some of which consists of latitudinally and longitudinally separated forms, which are found to be associated with pulsed ionospheric flows in merging and lobe convection cells. The auroral/convection events may be separated into different forms/cells and phases, reflecting a spatiotemporal evolution of the reconnection process on the dayside magnetopause. The initial phase consists of a brightening in the postnoon sector $(\sim 12: 00-14: 00 \mathrm{MLT})$ at $\sim 73^{\circ}$ MLAT, accompanied by a pulse of enhanced westward convection in the postnoon merging cell. Thereafter, the event evolution comprises two phenomena which occur almost simultaneously: (1) westward expansion of the auroral brightening (equatorward boundary intensification) across noon, into the $\sim 10: 00-12: 00$ MLT sector, where the plasma convection subsequently turns almost due north, in the convec-
\end{abstract}

Correspondence to: P. E. Sandholt

(p.e.sandholt@fys.uio.no) tion throat, and where classical poleward moving auroral forms (PMAFs) are observed; and (2) auroral brightening at slightly higher latitudes $\left(\sim 75^{\circ} \mathrm{MLAT}\right)$ in the postnoon lobe cell, with expansion towards noon, giving rise to a clear cusp bifurcation. The fading phase of PMAFs is accompanied by a "patch" of enhanced $(\sim 1 \mathrm{~km} / \mathrm{s})$ poleward-directed merging cell convection at high latitudes $\left(75-82^{\circ}\right.$ MLAT), e.g. more than $500 \mathrm{~km}$ poleward of the cusp equatorward boundary. The major aurora/convection events are recurring at $\sim 5-$ 10 min intervals.

Key words. Magnetospheric physics (auroral phenomena; magnetopause, cusp, and boundary layers; plasma convection)

\section{Introduction}

There is now increasing evidence supporting the view that plasma convection at dayside high latitudes under conditions of a dominant $B_{y}$ component consists of a composite pattern of so-called merging and lobe convection cells (Reiff and Burch, 1985; Knipp et al., 1993; Lu et al., 1994; Weiss et al., 1995; Crooker et al., 1998; Weimer, 2001; Eriksson et al., 2002). While the merging cells are characterized by the transfer of magnetic flux across the open-closed field line boundary (OCFLB) in the cusp region, the lobe cells circulate plasma in the polar cap region, entirely poleward of the OCFLB. Recent case studies have documented that these two types of plasma convection are accompanied by corresponding auroral forms (Sandholt et al., 1998b, c, 2001). The aurora associated with merging cell convection is characterized by a sequence of equatorward boundary intensifications from which emanate poleward moving auroral forms (PMAFs) (Sandholt et al., 1986; Fasel, 1995; Sandholt and Farrugia, 
1999; Sandholt et al., 2002). The sequential behaviour is considered to reflect the pulsed (intermittent) nature of magnetic reconnection at the magnetopause (Russell and Elphic, 1978; Cowley, 1984). The corresponding convection signature consists of pulsed flows in the cusp region ionosphere (Lockwood et al., 1989; Provan et al., 1999; Moen et al., 2001).

Initial case studies indicate that the auroral manifestation of the composite pattern of merging and lobe cells appears in the form of two latitudinally separated forms, called types 1 and 2, forming a so-called bifurcated cusp (Sandholt et al., 1998c, 2001), which corresponds to a double cusp in particle precipitation data (Wing et al., 2001; Sandholt et al., 2002). The detailed 2-D association between aurora and convection in this configuration is not well known at present. This association is the topic of the present paper.

The importance of $B_{y}$ for lobe reconnection and the resulting convection cells confined entirely to the polar cap has been highlighted for a purely positive IMF $B_{y}$ in magnetohydrodynamic (MHD) studies by, for example, Crooker et al. (1998) and White et al. (1998). The former study indicated that the IMF $B_{y}$ and $B_{x}$ components are more important controlling factors than IMF $B_{z}$. Moreover, the Alfvén Mach number seemed to control the relative strengths of the model lobe cell circulation relative to the normal dayside two-cell convection pattern. The larger the Alfvén Mach number is, the weaker the lobe cell strength.

Recently, a few observations of $B_{y}$-dominant IMF reconnection have been presented. Marcucci et al. (2000) reported an indirect observation of a long reconnection event detected by the Equator-S spacecraft for a dawn magnetopause skimming the orbit near the equatorial plane during a predominantly dawnward directed IMF with a southward $B_{z}$ component. Popescu et al. (2001) presented Interball Tail data of a reconnection event, also during mainly dawnward IMF, at the high-latitude dawnside flank, with a sunward-flowing plasma layer adjacent to the plasma mantle that lasted for many hours. The question of sub-Alfvenic versus superAlfvenic flow regimes along the magnetopause and the stability of the reconnection site have been addressed in a few publications. Adopting the antiparallel merging hypothesis to study the magnetopause location of quasi-steady and transient reconnection at the magnetopause, Rodger et al. (2000) concluded that the condition of fields being within $10^{\circ}$ of pure antiparallel alignment is met within a sub-Alfvénic region at the dusk (dawn) high-latitude Northern Hemisphere flank for an IMF of equal magnitudes of a positive (negative) $B_{y}$ and negative $B_{z}$.

Lobe cell convection during $\left|B_{y}\right|>\left|B_{z}\right|$ IMF conditions is characterized by sunward (zonal) polar cap convection in the postnoon (prenoon) sector for $B_{y}>0(<0)$ (Reiff and Burch, 1985; Lu et al., 1994; Eriksson et al., 2002). According to these studies, lobe cell convection is present for both positive and negative $B_{z}$ polarity so long as $\left|B_{y}\right| \geq\left|B_{z}\right|$. Furthermore, in their recent case study based on data from the FAST satellite, Eriksson et al. (2002) show that the zone of sunward (zonal) lobe cell convection is accompanied by a patch of precipitating magnetosheath plasma with the presence of strong field-aligned currents (of opposite polarity) at its northern and southern boundaries, within the $79^{\circ}-$ 82 $2^{\circ}$ MLAT/13:00-14:00 MLT sector $\left(B_{y}>0\right)$ in the summer hemisphere (see their Plate 3). In this study we are taking advantage of the ability of ground-based observations to reveal the spatiotemporal variability of auroral precipitation and convection referring to the same sector/phenomenon. However, our observations are performed in the winter hemisphere.

At present, there is an ongoing debate about where reconnection takes place at the magnetopause during strong IMF $B_{y}$ conditions. One view is that reconnection in such cases can occur where there are antiparallel components in the external magnetosheath magnetic field and the Earth's field (Gonzalez and Mozer, 1974; Cowley, 1981; Sonnerup, 1984; Taguchi et al., 1993; Kawano and Russell, 1997; Siscoe et al., 2001). According to this view, reconnection can take place over large areas of the dayside magnetopause, for example, along a tilted reconnection line traversing the subsolar region and extending to high latitudes in both hemispheres. In the antiparallel model, on the other hand, reconnection is restricted to high latitudes during $B_{y}$-dominated IMF conditions (Crooker, 1979; Luhmann et al., 1984; Rodger et al., 2000; Coleman et al., 2001). Auroral observations of relevance to this issue are reported in this paper.

By combining observations from two similar all-sky imagers with partly overlapping fields of view in the east-west direction, we have been able to study the 2-D evolution of auroral forms in the cusp region, around magnetic noon, and in the postnoon sector of the polar cap. The continuous groundbased monitoring by this technique allows us, in this case study, to demonstrate the detailed spatiotemporal evolution of auroral precipitation and plasma convection when the latter consists of a composite pattern of merging and lobe cells, during a long interval of $B_{y}>0$ and $B_{z}<0$ conditions.

The detailed observations of the evolution of the auroral events, including poleward moving/expanding auroral forms (PMAFs), are placed in the proper context of large-scale plasma convection at high temporal and spatial resolution. First of all, we demonstrate a close association between the sequence of auroral brightenings/PMAFs and pulsed ionospheric flows (Provan et al., 1999; Greenwald et al., 1999; Provan et al., 2002). Each episode of enhanced merging cell convection may be divided in two phases, for example, (i) enhanced westward convection at the cusp equatorward boundary, followed by, (ii) a "patch" of strong $(\sim 1 \mathrm{~km} / \mathrm{s})$, poleward convection at high latitudes, $>500 \mathrm{~km}$ poleward of the cusp equatorward boundary. The corresponding phases of cusp auroral activity are: (i) equatorward boundary intensification (initial appearance in the postnoon sector followed by rapid expansion across noon) and (ii) poleward moving/expanding auroral form in the 10:00-12:00 MLT sector.

We note that ion flow velocities are observed to increase poleward of the cusp during these poleward propagating events. Phases (i) and (ii) of the ionospheric auroral-convection events are considered to be manifesta- 


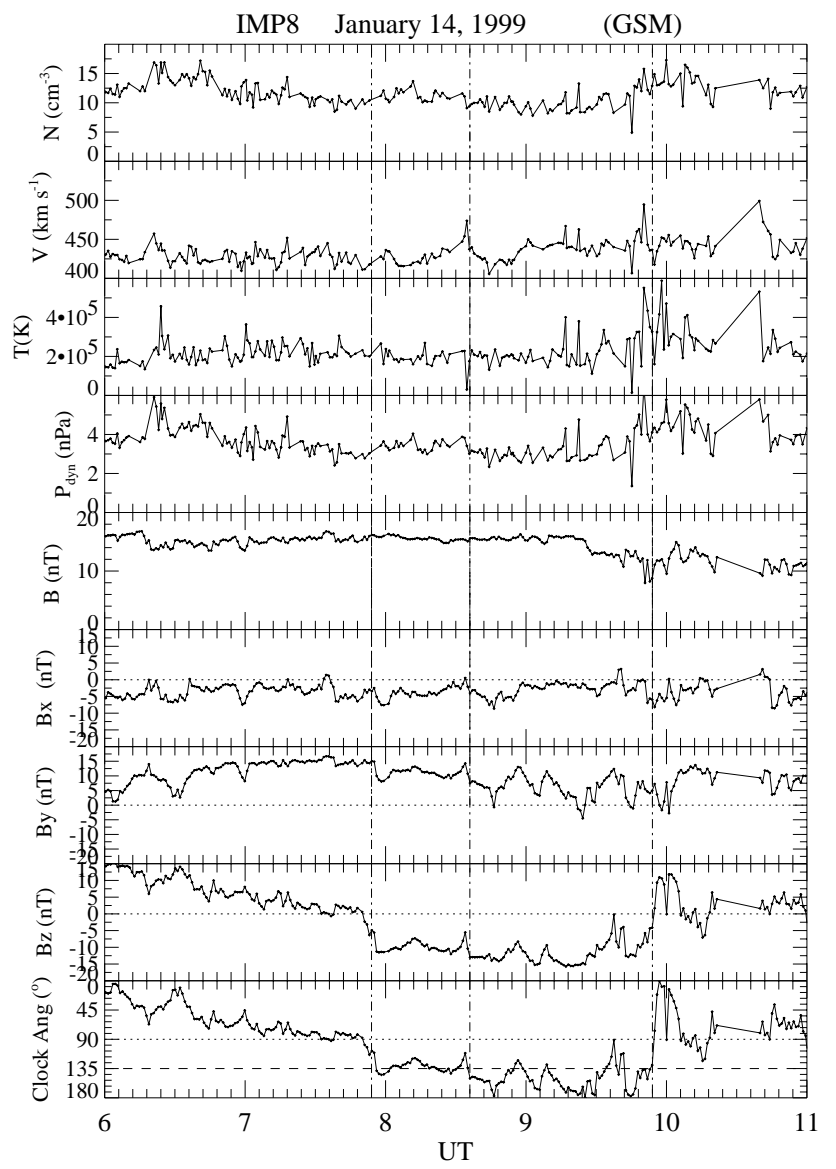

Fig. 1. Interplanetary magnetic field (IMF) and solar wind plasma data obtained from spacecraft IMP8 during the interval 06:0011:00 UT on 14 January 1999. Panels from top to bottom show proton density, bulk speed, proton temperature, dynamic pressure, field intensity, and GSM $X, Y$, and $Z$ components, and the clock angle. IMF regimes are marked by vertical guidelines (see text).

tions of bursty/pulsed dayside magnetopause reconnection and the subsequent tailward motion of reconnected field lines. The high-latitude phase (ii) observations appear as the recently reconnected field lines are being pulled antisunward by the magnetosheath flow. The observed flow excitation in this phase is in agreement with the previous observations/interpretations reported by for example, Sandholt et al. (1993) and Provan et al. (2002). PMAFs are found to be tracers of electron precipitation along poleward moving flux tubes in the convection throat which are present during a $\sim 5$ min long phase following the initial equatorward boundary intensification.

The presence of a stepped cusp particle precipitation observed by polar orbiting, low-altitude spacecraft (Escoubet et al., 1992) during an interval of sequential auroral brightenings/PMAFs, an association first documented by Yeoman et al. (1997) and Farrugia et al. (1998), is confirmed in this study. In the present case the cusp was observed to be permeated by thin filaments of electron precipitation containing a rather broad energy spectrum $(\sim 30 \mathrm{eV}-1 \mathrm{keV}$; average en-

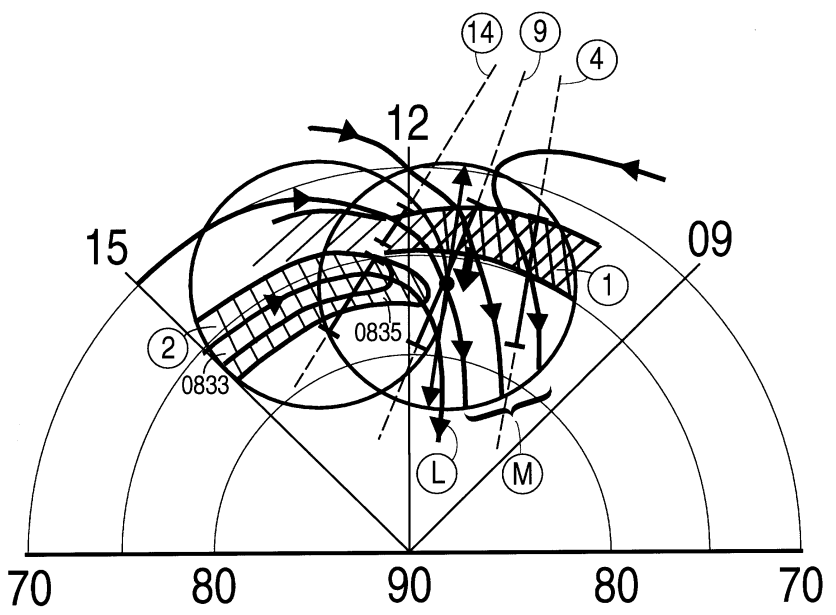

Fig. 2. Schematic overview of the observations of aurora (hatched areas) and convection (with merging (M) and lobe (L) cells), representing the interval 08:33-08:38 UT on 14 January 1999 . The coordinate system is magnetic local time (MLT)/ magnetic latitude (MLAT). Approximate fields of view of auroral all-sky imagers at Ny Ålesund, Svalbard and Heiss Island, Russia, are marked by circles. Arrowed meridional line indicate the field of view of the meridian scanning photometer (MSP) in Ny Ålesund ( $76.1^{\circ}$ MLAT). Beams 4, 9, and 14 of the CUTLASS Finland radar are indicated, as well as different auroral forms.

ergy $200 \mathrm{eV})$. The latter is consistent with the long auroral rays which are so typical in the cusp region.

\section{Data presentation}

Figure 1 shows interplanetary magnetic field and plasma data observed by the IMP8 spacecraft during the interval 06:0011:00 UT on 14 January 1999. At 08:00 UT IMP8 was located at $(-1.9,-33.6,-9.4) R_{E}$, e.g. the spacecraft was in the solar wind near the dawn terminator. $B_{y}$ was strongly positive (10-15 nT) throughout, except for three brief excursions to zero, or slightly negative between 09:20-10:00 UT. $B_{x}$ was negative. We note the southward (at 07:50 UT) and northward turnings at 09:54 UT, marked by the first and third vertical guidelines. The same major features are observed from spacecraft ACE, located at $(233,36,8) R_{E}$. The mentioned rapid and strong northward turning was recorded by ACE at 08:40 UT, i.e. 74 min earlier than IMP8. Both spacecraft recorded a solar wind bulk speed of $420-430 \mathrm{kms}^{-1}$ and density (dynamic pressure) of $10 \mathrm{~cm}^{-3}(4 \mathrm{nPa})$. The ground magnetic effect of the northward turning at 09:54 UT (IMP8 time) is clearly observed in the local magnetograms from the Svalbard IMAGE stations at 10:00 UT. The propagation delay from IMP8 to the ground is about $5-10 \mathrm{~min}$ in this case. We shall be concerned with the auroral activity in the cusp region during the interval 08:10-08:50 UT, when the IMF is characterized by a negative $(-10 \mathrm{nT}) B_{z}$ component and a positive (10nT) $B_{y}$ component. This is the interval between the first two vertical guidelines in Fig. 1. The clock angle 
(polar angle of the IMF vector projected into the GSM $Y-Z$ plane) is $\sim 135^{\circ}$.

Figure 2 shows the observation geometry at $\sim 08: 35$ UT superposed on a schematic convection pattern consisting of merging $(\mathrm{M})$ and lobe $(\mathrm{L})$ cells. Arrowed meridional lines and circles mark the fields of view (FOV) of the meridian scanning photometer (MSP) and the all-sky camera, respectively, in Ny Ålesund, Svalbard (76.1 ${ }^{\circ}$ MLAT). The FOV of the all-sky camera at Heiss Island, located $\sim 700 \mathrm{~km}$ to the east of Svalbard, is marked by the second circle (to the left).

Hatched areas mark two latitudinally and longitudinally separated cusp-type auroral forms, labelled 1 and 2. Strong red line emission in the type 1 cusp aurora in the convection throat in the 10:00-11:30 MLT sector during 08:3608:38 UT is marked by cross-hatching. The westward expansion of the type 2 form into the eastern part of the field of view at Ny Ålesund during 08:33-08:35 UT, as well as the poleward expansion of type 1 auroras during 08:3508:38 UT, are indicated. Regions of strong backscatter along beams 4, 9, and 14 of the CUTLASS Finland HF radar are marked by bars along the respective anntenna beams.

Figure 3 shows MSP observations of the auroral emission lines at $630.0 \mathrm{~nm}$ (panel a) and $557.7 \mathrm{~nm}$ (panel b) taken at Ny Ålesund $\left(76.1^{\circ} \mathrm{MLAT}\right)$ during the interval 08:00 09:00 UT (11:00-12:00 MLT) on 14 January 1999. Line of sight intensities are colour-coded according to the scales at the bottom of each panel. The MSP FOV for the red line emission (at 08:30 UT/ 11:30 MLT) is indicated in Fig. 2. The auroral equatorward boundary is located well to the south of Ny Ålesund and is moving slightly equatorward during the interval shown. We focus on the four strong brightening events (red) recorded during 08:20-08:50 UT (08:25, 08:35, 08:41/42, and 08:49 UT). Three of these events show a characteristic poleward expansion of luminosity. Each event consists of the following substructure, when moving from lower to higher latitude (from bottom to top in the MSP panels):

1. green line enhancements near the southern horizon, at $70^{\circ}-80^{\circ} \mathrm{SZ}$ (south of zenith) (the corresponding red line emission is very weak),

2. strong brightening of a band located at $\sim 40-60^{\circ} \mathrm{SZ}$, appearing in both emission lines, often in the form of two subsequent brightenings,

3. one or two "re-brightenings" closer to the zenith $\left(30^{\circ}-\right.$ $0^{\circ} \mathrm{SZ}$ ), related to the poleward expansion of luminosity.

As we shall see below, the "re-brightening" phenomenon can be the result of the expansion of type 2 events into the MSP FOV, from the east (postnoon) side. The events typically recur at $5-10 \mathrm{~min}$ intervals. The 2 -D evolution of the activity in the interval 08:30-08:38 UT will be shown below, revealing that the type 2 auroral brightening/expansion events are accompanied by zonal flow towards noon from dusk, in the polar cap.
In order to illustrate the transition in auroral emission along the Ny Ålesund meridian which took place at 08:5509:00 UT (12:00 MLT), we show in Fig. 4 a red line plot for the interval 08:00-10:00 UT. The aurora along the Ny Ålesund meridian changed latitudinal position and character when the local meridian rotated with the Earth into the postnoon sector. After 09:00 UT, the aurora is located further to the south, and the poleward moving forms are not such a dominant feature as in the interval 08:00-09:00 UT.

Figure 5 shows an all-sky image sequence of the $630.0 \mathrm{~nm}$ aurora observed at Ny Ålesund during the interval 08:3108:39 UT. The Ny Ålesund all-sky camera FOV for the red line emission (at $\sim 08: 30 \mathrm{UT}$ ) is indicated in Fig. 2. This sequence shows the 2-D evolution of one of the four major auroral events recorded by the MSP plot during the interval 08:25-08:50 UT (Fig. 3). Two features are clearly manifest:

1. the appearance of a bright form (rayed band) in the eastern part of the FOV at 08:32 UT (type 2 aurora), which expands westward and poleward, reaching the MSP meridian at $\sim 08: 36 \mathrm{UT}$, and fading out during 08:36-08:38 UT,

2. brightening in the southwestern part of the FOV during 08:34-08:37 UT (type 1 aurora; marked as crosshatched area in Fig. 2). The latter appears as a red line intensification at $45^{\circ} \mathrm{SZ}-60^{\circ} \mathrm{SZ}$ in Fig. 3 .

A closer view of the evolution of the auroral activity in the 12:00-15:00 MLT sector during the interval 08:30-08:38 UT is provided by the image sequence shown in Fig. 6, obtained from the Russian station Heiss Island (HI), located at $80.6^{\circ} \mathrm{N} ; 58.1^{\circ} \mathrm{E}\left(75.2^{\circ} \mathrm{MLAT}\right)$. This location is $\sim 700 \mathrm{~km}$ to the east of Ny Ålesund. The approximate FOV of this camera (at $630.0 \mathrm{~nm}$ ) is indicated in Fig. 2. The center of the FOV of the HI camera is located at the eastern boundary of the Ny Ålesund camera. The HI camera, therefore, effectively extends the FOV in the eastward direction to include (in our case) the $\sim 13: 00-15: 00$ MLT sector.

The initial brightening, located in the $\sim 13: 00-15: 00$ MLT sector, is seen in the third (08:31:38 UT) image in Fig. 6. The brightening continues in the next image (08:32:46 UT). This is followed by a clear auroral bifurcation which is evident in the 08:33:56 UT image and onwards, characterized by a type 1 aurora in the southwestern part of the HI FOV and the type 2 form expanding westward across the whole FOV further north. The western boundary of the type 2 event expanded westward from Heiss Island (center of the FOV) to Svalbard during the interval 08:32-08:35 UT. Thus, this form entered the FOV of the Ny Ålesund meridan scanner, slightly south of the zenith, at 08:35UT. The fading phase of this event is represented by the lower row of pictures in Fig. 6, covering the interval 08:36:17-08:38:40 UT. Main features of the auroral activity during the interval 08:33-08:38 UT are schematically summarized in Fig. 2.

Figure 7 shows line of sight ion drift velocities obtained by beams 4 (upper panel), 9 (middle), and 14 (bottom) of the Cutlass Finland HF radar during the interval 08:00-09:00 UT 


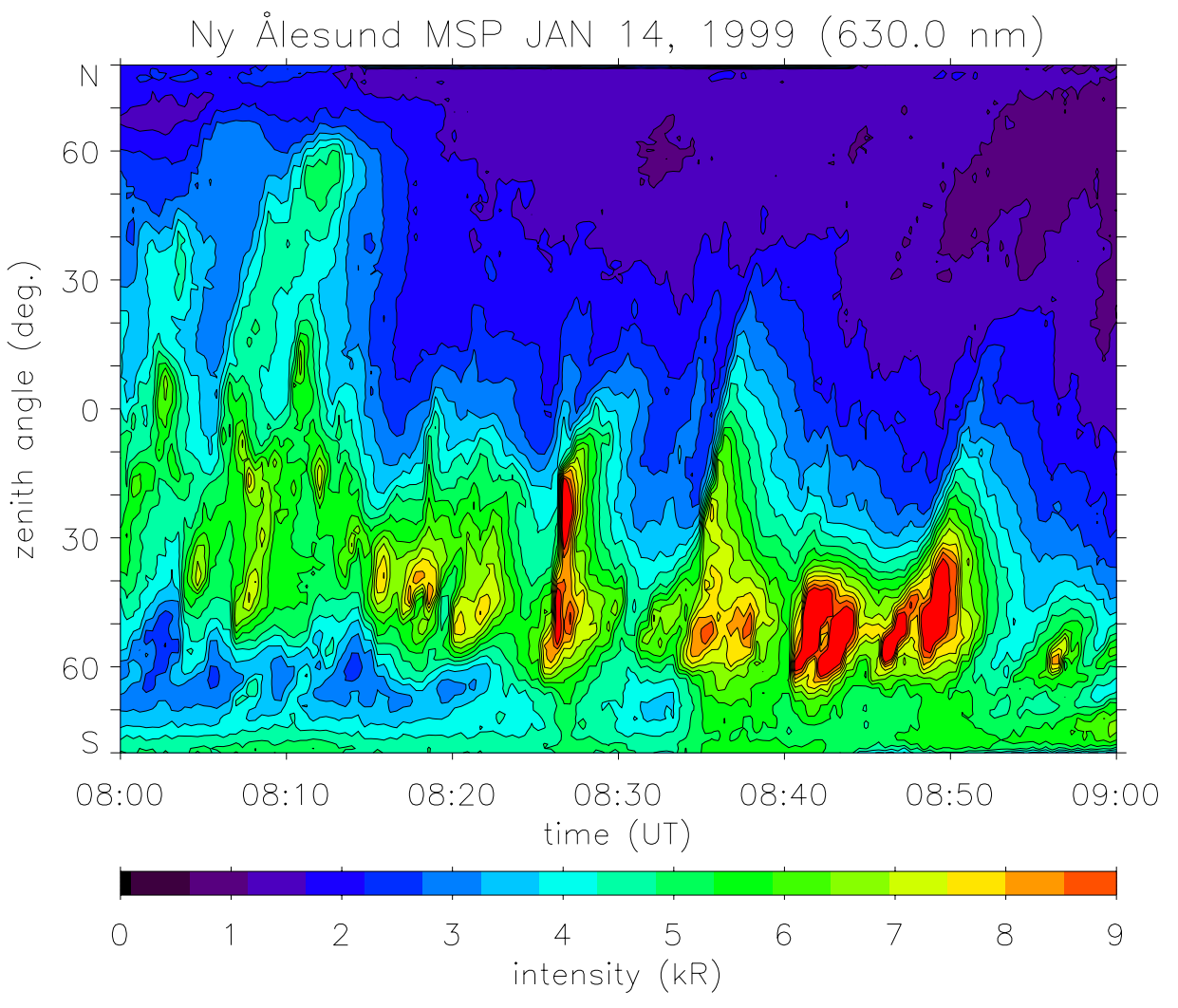

(a)

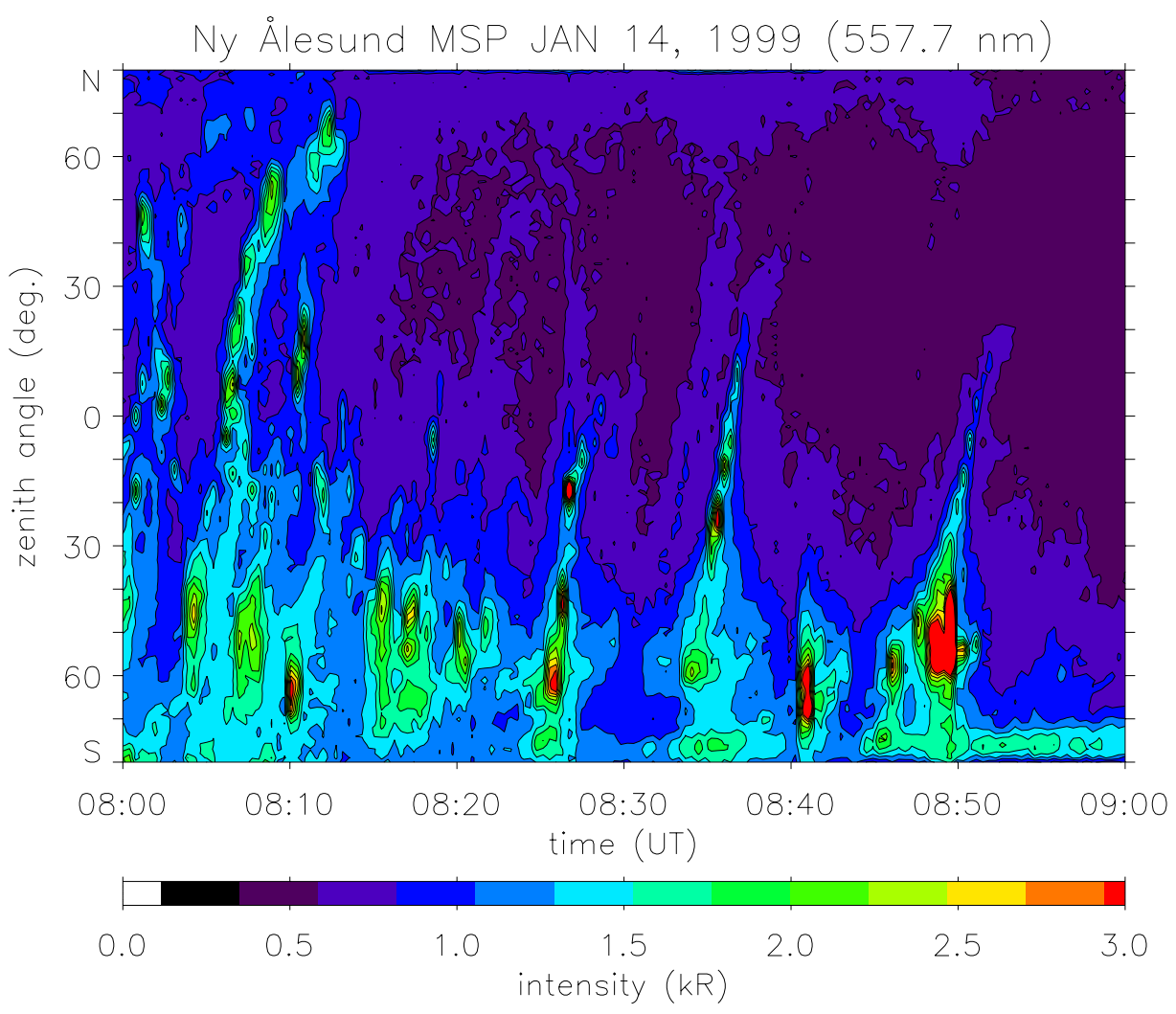

Fig. 3. Meridian scanning photometer line of sight intensities versus zenith angle, at $630.0 \mathrm{~nm}$ (a) and $557.7 \mathrm{~nm}$ (b), for the interval 08:0009:00 UT on 14 January 1999. Intensities are colour-coded according to the scale at the bottom. 


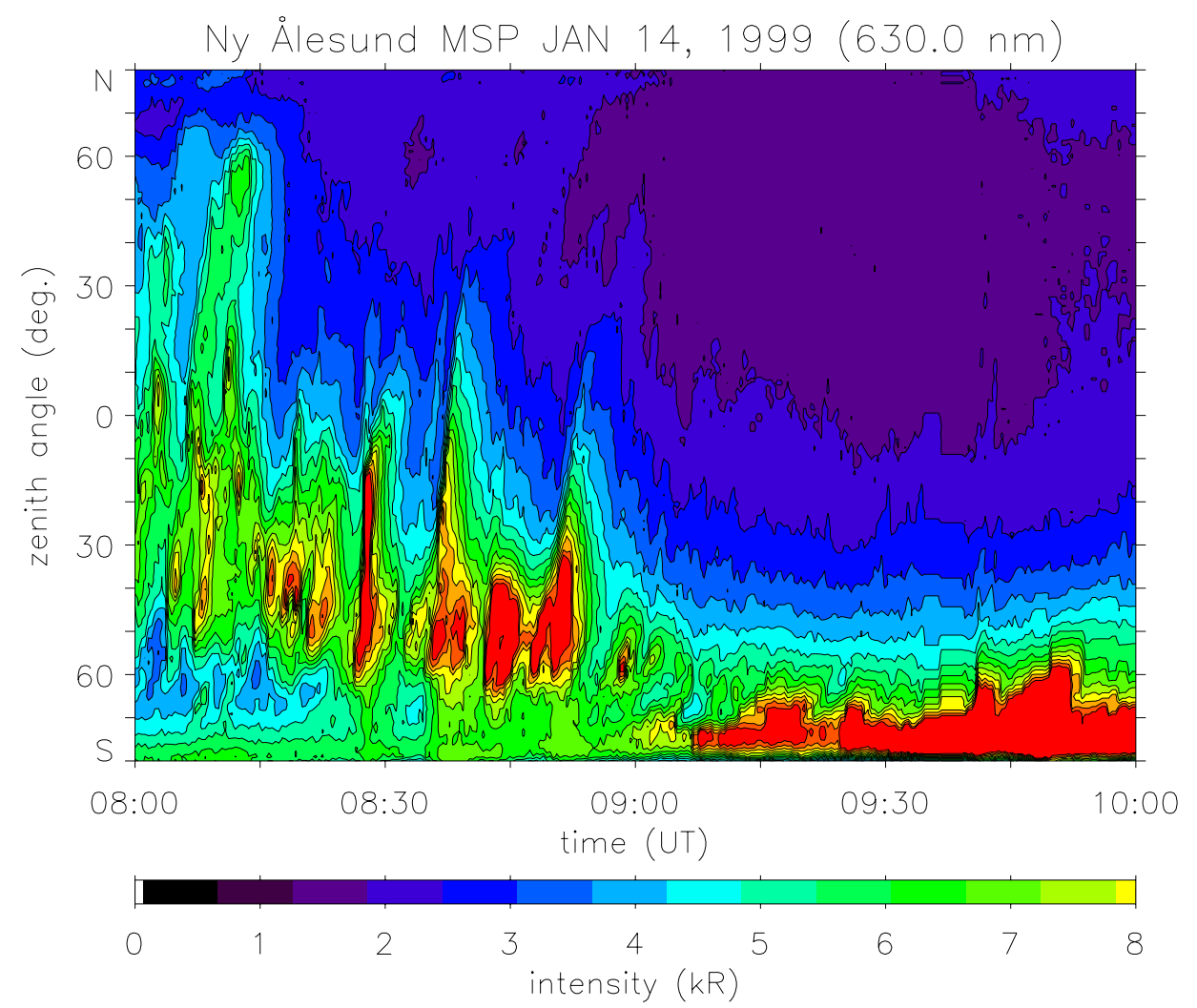

Fig. 4. Meridian scanning photometer line of sight intensities versus zenith angle, at $630.0 \mathrm{~nm}$, for the interval 08:00-10:00 UT on 14 January 1999. Intensities are colour-coded according to the scale at the bottom.
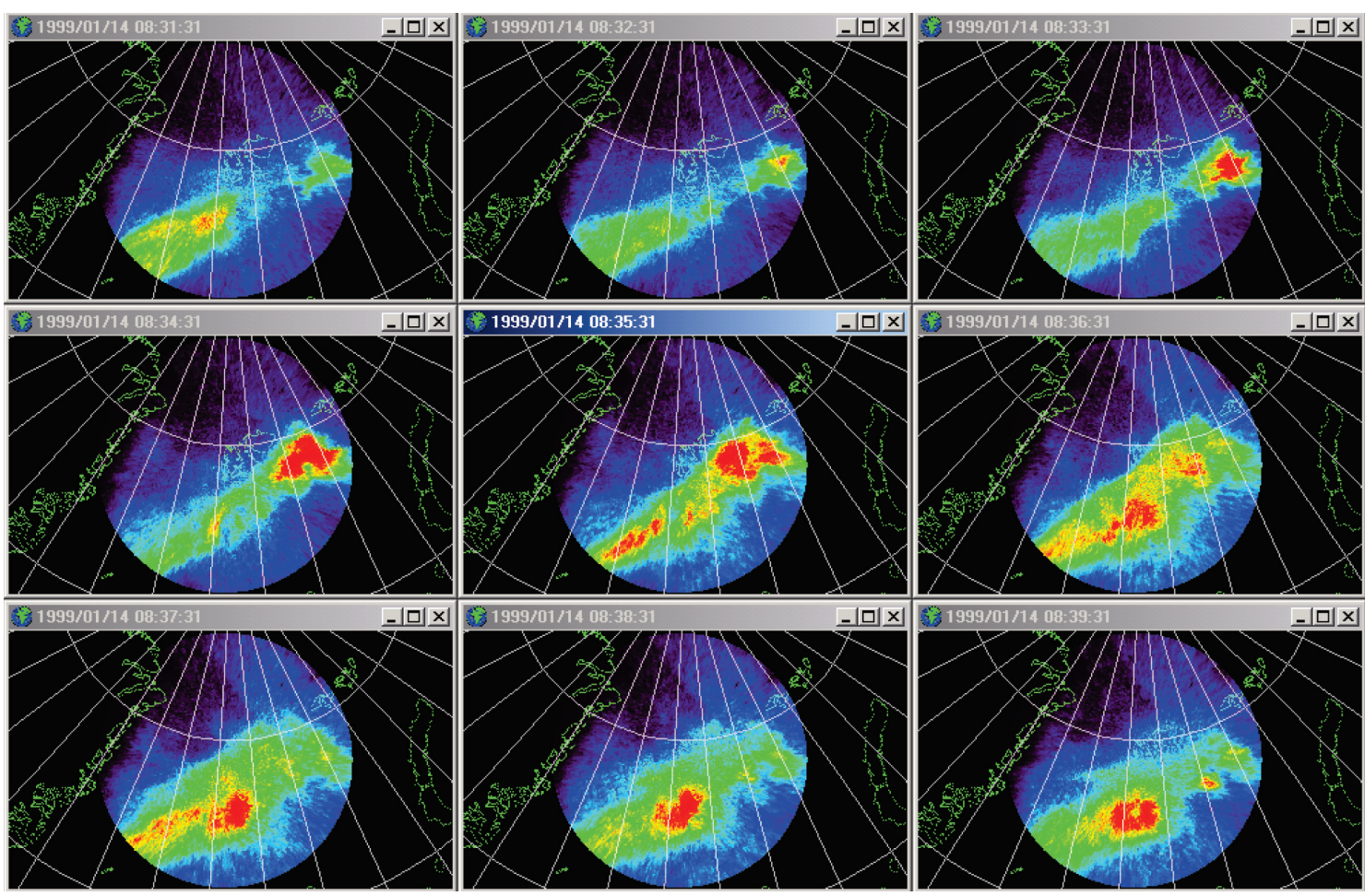

Fig. 5. Ny Ålesund all-sky camera images at $630.0 \mathrm{~nm}$ taken at 08:31:31;08:32:31;08:33:31;08:34:03; 08:35:31; 08:36:31, 08:37:31, 08:38:31, and 08:39:31 UT. Each image is projected to an altitude of $250 \mathrm{~km}$ and shown on the background of a geographic coordinate system. The $70^{\circ}$ and $80^{\circ}$ latitude circle and meridians separated by $10^{\circ}$ are shown. 

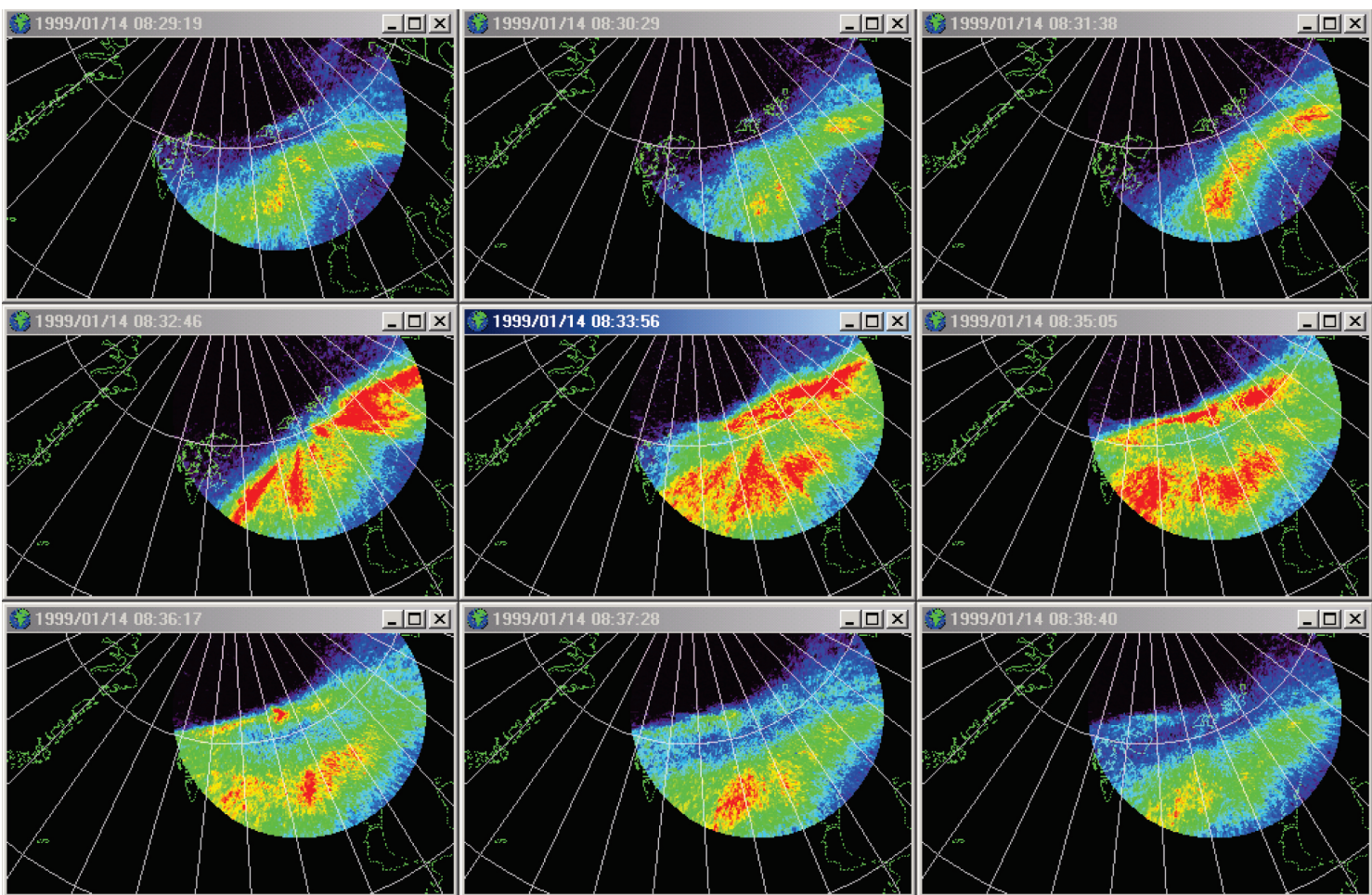

Fig. 6. Heiss Island all-sky camera images at 630.0 nm taken at 08:29:19; 08:30:29; 08:31:38; 08:32:46; 08:33:56; 08:35:05; 08:36:17; 08:37:28; and 08:38:40 UT, projected to an altitude of $250 \mathrm{~km}$ and shown on the background of a geographic coordinate system. Same format as in Fig. 5.

on 14 January 1999. The fields of view of these radar beams are indicated in Fig. 2. The four auroral brightening events observed by the Ny Ålesund MSP during the interval 08:2508:50 UT, seen in Fig. 3, are marked by vertical dashed guidelines. Strong line of sight flows away from the radar (red) are recorded in both the upper (beam 4) and middle (beam 9) panels after 08:25 UT. The equatorward boundary of the region of enhanced backscatter in beam 9 (the beam located closest to the MSP FOV) migrated equatorward from $75^{\circ}$ to $72^{\circ}$ MLAT during 08:00-08:50 UT, and then expanded down to $70^{\circ}$ MLAT by 09:00 UT. This backscatter boundary and its motion correspond closely with the equatorward boundary of the type 1 cusp aurora (see Fig. 3). A pulsed nature of the away (antisunward) flow, roughly corresponding to the auroral brightenings marked by the vertical guidelines, is seen in beams 4 and 9 .

The easternmost beam (14; bottom panel) shows four patches of line of sight flows toward the radar (green and blue), within 73-78 MLAT, during 08:20-08:50 UT. These events are centered at the times of the marked auroral events. At this point we note that the CUTLASS beam 14 overlaps with the eastern part of the Ny Ålesund all-sky camera field of view and the western part of the Heiss Island camera field of view. The initial phase of these radar events (within $73-75^{\circ}$ MLAT), representing westward convection (also containg an equatorward component), corresponds to the initial auroral brightening in the same region. We also note in the beam 14 data the presence of transient events of away flow (red) at the equatorward boundary of the region of backscatter at the time of the type 1 auroral brightening events (the vertical lines). There are some spurious positive (blue) Doppler shift echoes mixed in with the general negative (red) Doppler shift flow.

Returning to the 08:32-08:38 UT event, we observe the following association between aurora and ion drift. At 08:35 UT (second vertical guideline in Fig. 7), beam 14 recorded an away (line of sight) flow (red) at $73^{\circ}$ MLAT, near the equatorward boundary of the (type 1) aurora in the 12:00-13:00 MLT sector, and a toward flow (blue) between $75^{\circ}-78^{\circ}$ MLAT, in the region of the type 2 expansion event (see Figs 6 and 2). This association of aurora-convection is seen in most events. We also notice that each individual patch of toward (blue) flow typically expands poleward during the event (see, for example, the interval 08:32-08:38 UT). Each event (blue patch) is associated with auroral forms (type 2) expanding towards Svalbard, from the eastern (postnoon) side. The aurora corresponding to the 08:32-08:38 UT event is shown in Figs. 5 and 6.

The spatial structure of the convection pattern and its evolution during the interval 08:32-08:42 UT are shown in Fig. 8. The coordinate system is magnetic local time (MLT) and magnetic latitude (MLAT). To construct the 2-D flow pattern from the radar line of sight velocities, we employ the analysis technique developed by Ruohoniemi and Baker (1998) (see also Greenwald et al., 1995). This technique determines the solution for the distribution of electrostatic potential expressed as a series expansion in spherical harmonics (in our case of the order of 10), constrained by the line 


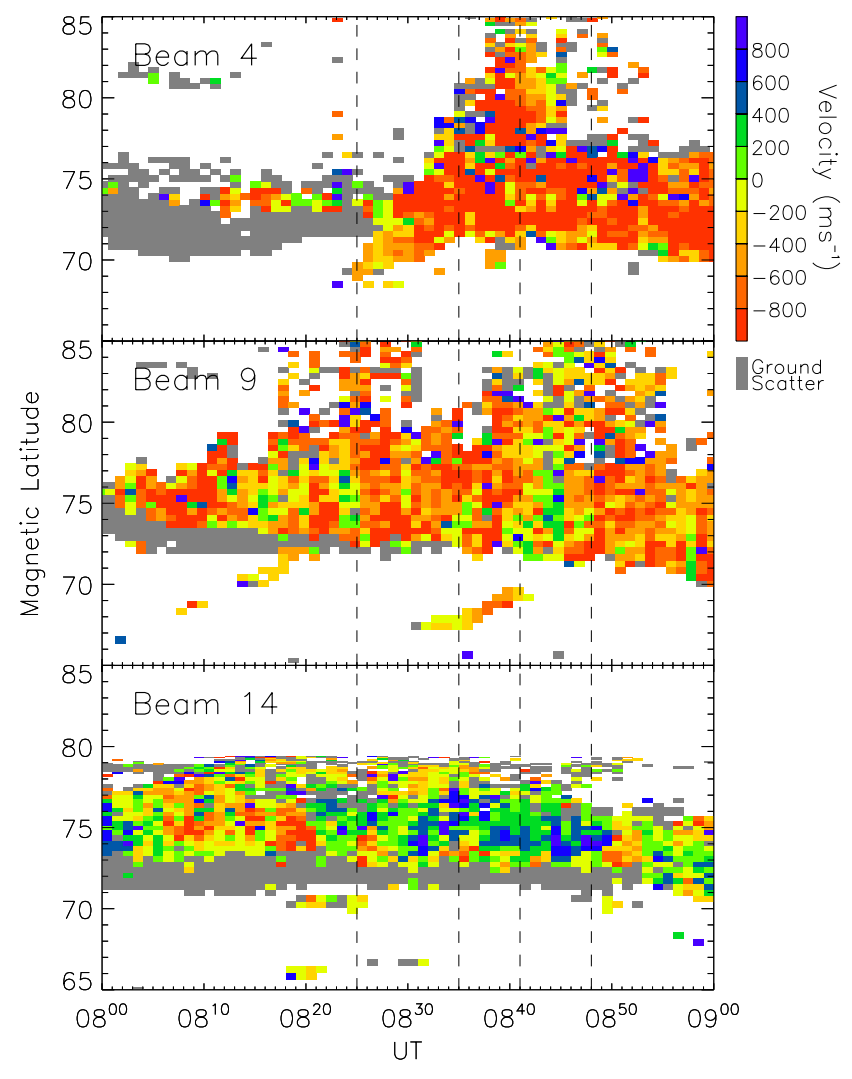

Fig. 7. Line of sight ion drift velocities as a function of magnetic latitude and time, obtained from beams 4, 9, and 14 of the CUTLASS HF radar during 08:00-09:00 UT. Velocities are colour-coded according to the scales to the right. Four successive auroral brightening events are marked by vertical guidelines at 08:25, 08:35, 08:41, and 08:48 UT.

of sight measurements of the radars. Contours of the electrostatic potential so derived are superimposed, which, in effect, represent convection flow streamlines. In regions where no radar backscatter is present, the potential solution is driven by a statistical convection model, which may not accurately reflect the instantaneous flows occurring in the ionosphere. However, in regions where backscatter is present, thus constraining the solution, the contours represent a flow pattern that accurately reflects the line-of-sight measurements.

From Fig. 8 we note the following three features of the evolution of the event:

1. The initial (08:32-08:34 UT) westward convection in the 12:00-14:00 MLT/ $73-75^{\circ}$ MLAT sector which is accompanied by a clear local auroral brightening (see Fig. 6);

2. The strong (red) poleward flow in the 10:0011:30 MLT $/ 73^{\circ}-78^{\circ}$ MLAT sector during 08:3408:38 UT. The corresponding aurora consists of an equatorward boundary intensification (EBI) at $\sim 73^{\circ}$ from which emanates a poleward moving auroral form (PMAF). These observations strongly indicate that there is a close association between the auroral phenomenon (EBI-PMAF) (see Fig. 3) and enhanced poleward flow in the convection throat. The brightest type 1 aurora during 08:34-08:39 UT is confined to the western side of the Ny Ålesund meridian, as is seen in Fig. 5;

3. The westward convection in the lobe cell (blue) in the postnoon sector (12:00-15:00 MLT/ 75-77 MLAT) during 08:34-08:38 UT (Fig. 8).

This is accompanied by the westward expansion of the type 2 aurora (Fig. 6). The spatial relationship between the two auroral forms (called types 1 and 2 ) and the convection pattern at this time is illustrated in Fig. 9. We note that the sunward flow in the postnoon sector (blue), containing an equatorward component, is in accordance with the MHD modelling work by Crooker et al. (1998) (see their Fig. 3).

The detailed association between aurora and convection for 08:36 UT (in MLT/MLAT coordinates) is illustrated in Fig. 10. The two auroral forms labelled 1 and 2 in Fig. 9 are easily identified. The aurora seen in the postnoon sector (12:30-14:30 MLT), well separated from the type 2 form on its equatorward side (within $\sim 72-74^{\circ}$ MLAT), is accompanied by northwestward convection in the merging cell. The latitudinal gap between this form (type 1) and the type 2 aurora also represents the separation between the merging and lobe convection cells. Poleward moving auroral forms are localized in the convection throat in the 10:00-12:00 MLT/73$77^{\circ}$ MLAT sector.

The evolution of the convection during the interval 08:3608:38 UT is illustrated in Fig. 11. We note the patch of strong poleward ion drift (red vectors) in the 75-82 ${ }^{\circ}$ MLAT 10:0012:00 MLT range. The bright cusp aurora in this local time sector (10:00-12:00 MLT) is shown in Fig. 5.

The association between plasma convection, particle precipitation and auroral forms during one of the events is indicated in Fig. 12. The figure shows the convection pattern for 08:38-08:40 UT with the trajectory of spacecraft DMSP F14 during 08:36-08:42 UT and the approximate field of view of the MSP in Ny Ålesund marked by dark blue symbols. Precipitating protons with energy-latitude dispersion typical of the cusp-mantle region during southward IMF conditions (energy increasing with decreasing latitude) was recorded from F14 in the sector marked by a red double-arrowed line (during 08:39:00-08:40:20 UT). In this same sector the ion driftmeter on board the spacecraft recorded strong, westward ion drift, i.e. a classical convection channel, after exiting a region of near zero drift in the direction normal to the S/C trajectory (during 08:36-08:38 UT). The spacecraft skimmed the boundary of the lobe cell during $\sim 08: 35-08: 38: 30$ UT. The strong sunward/equatorward convection within 08:3508:37 UT is one manifestation of the lobe cell. The latitudinal sector of the auroral brightening (equatorward boundary intensification) at $\sim 08: 40 \mathrm{UT}$, as recorded by the MSP in Ny Ålesund (Fig. 3), is marked by a red double-arrowed line along the MSP FOV.

At 08:40 UT the poleward boundary of the previous auroral brightening/poleward expanding event had reached well 

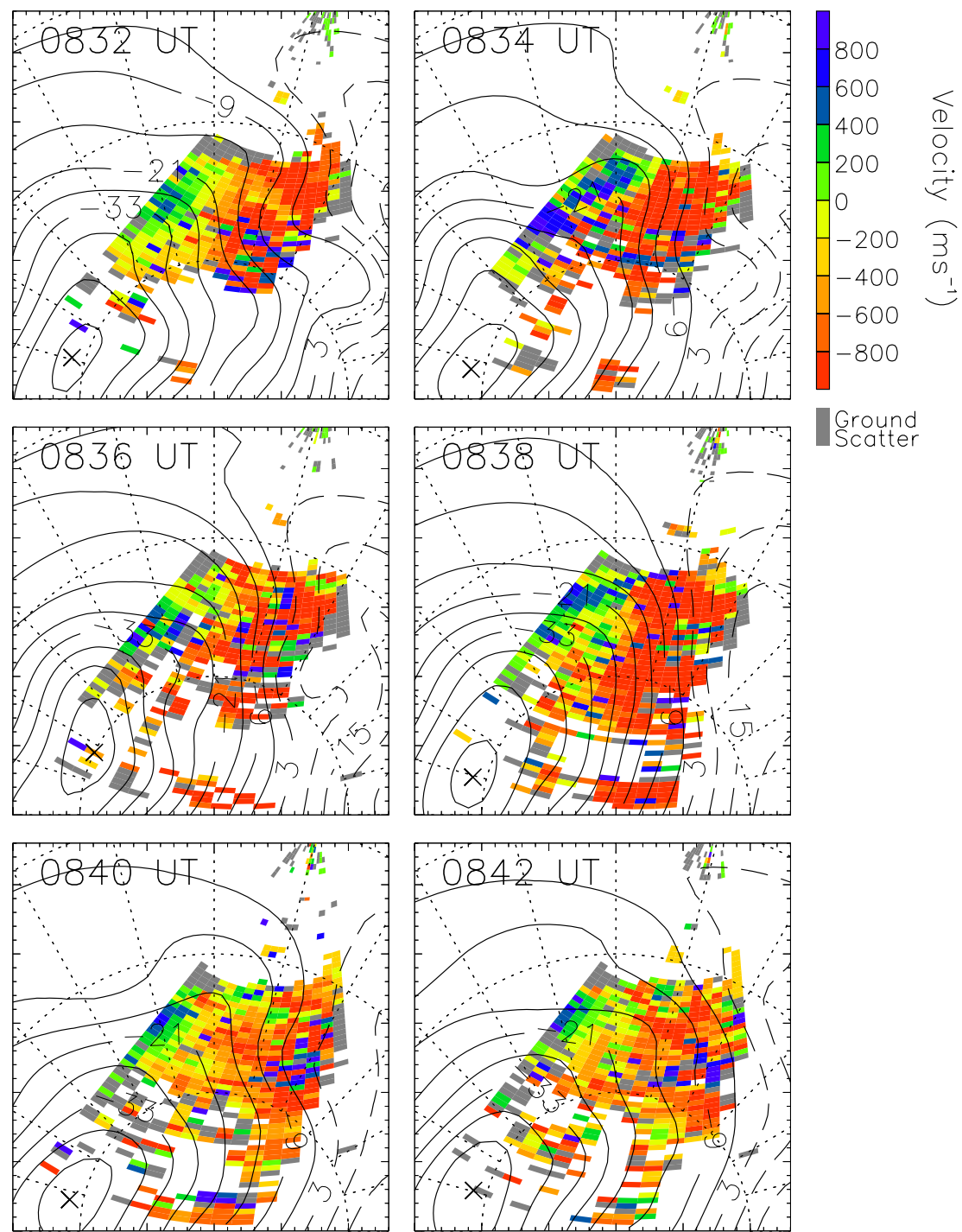

Fig. 8. Cutlass spatial plot of line of sight velocities from all 14 beams for the interval 08:32-08:42 UT. Velocities are color-coded according to the scale to the right. Superimposed are plasma flow streamlines. The coordinate system is MLT/MLAT. 12 MLT is at the top. Latitude circles at 60, 70, and $80^{\circ}$ MLAT are shown. beyond the latitude of Ny Ålesund (marked by an isolated solid dot in the figure). At this time Ny Ålesund is located near the eastern boundary of the region of enhanced $(>800 \mathrm{~m} / \mathrm{s})$ poleward ion drift in the convection throat. This data set demonstrates:

(i) that the poleward part of the cusp aurora, appearing as a classical PMAF, is expanding poleward in the direction of plasma convection in the throat region,

(ii) the episode of enhanced convection (08:32-08:40 UT) may be divided in two phases (enhanced westward convection at the cusp equatorward boundary, followed by a poleward propagating patch of strong, poleward convection) corresponding to two phases of the cusp auroral activity (equatorward boundary intensification, followed by a poleward moving/expanding form),

(iii) the fading phase of one event (08:38-08:40 UT) overlaps with the initial phase of the next event, and (iv) the patch of enhanced poleward ion drift is located within $75-82^{\circ}$ MLAT, e.g. it extends beyond the poleward boundary of the PMAFs in the fading phase.

Figure 13 shows the DMSP F14 data obtained during the pass indicated in Fig. 12. A clear staircase cusp with three ion energy steps was recorded during the interval 08:39:0008:40:30 UT. Low-energy cutoffs in these three steps are observed at $150 \mathrm{eV}, 500 \mathrm{eV}$, and $2 \mathrm{keV}$ (see panel 4). Thus, these steps are very similar to those reported by Escoubet et al. (1992), which were interpreted in terms of a pulsed magnetopause reconnection process and the associated poleward/tailward motion of a series of discrete, open flux tubes, which is due to the coupling to the solar wind. Within the regime of the stepped cusp $\left(\sim 71.5-74.0^{\circ}\right.$ MLAT/ $\sim 12.0$ 13.5 MLT), there is highly structured electron precipitation characterized by latitudinally separated filaments containing a broad energy spectrum, extending to relatively high energies $(600 \mathrm{eV}$ and occasionally above $1 \mathrm{keV}$; see 


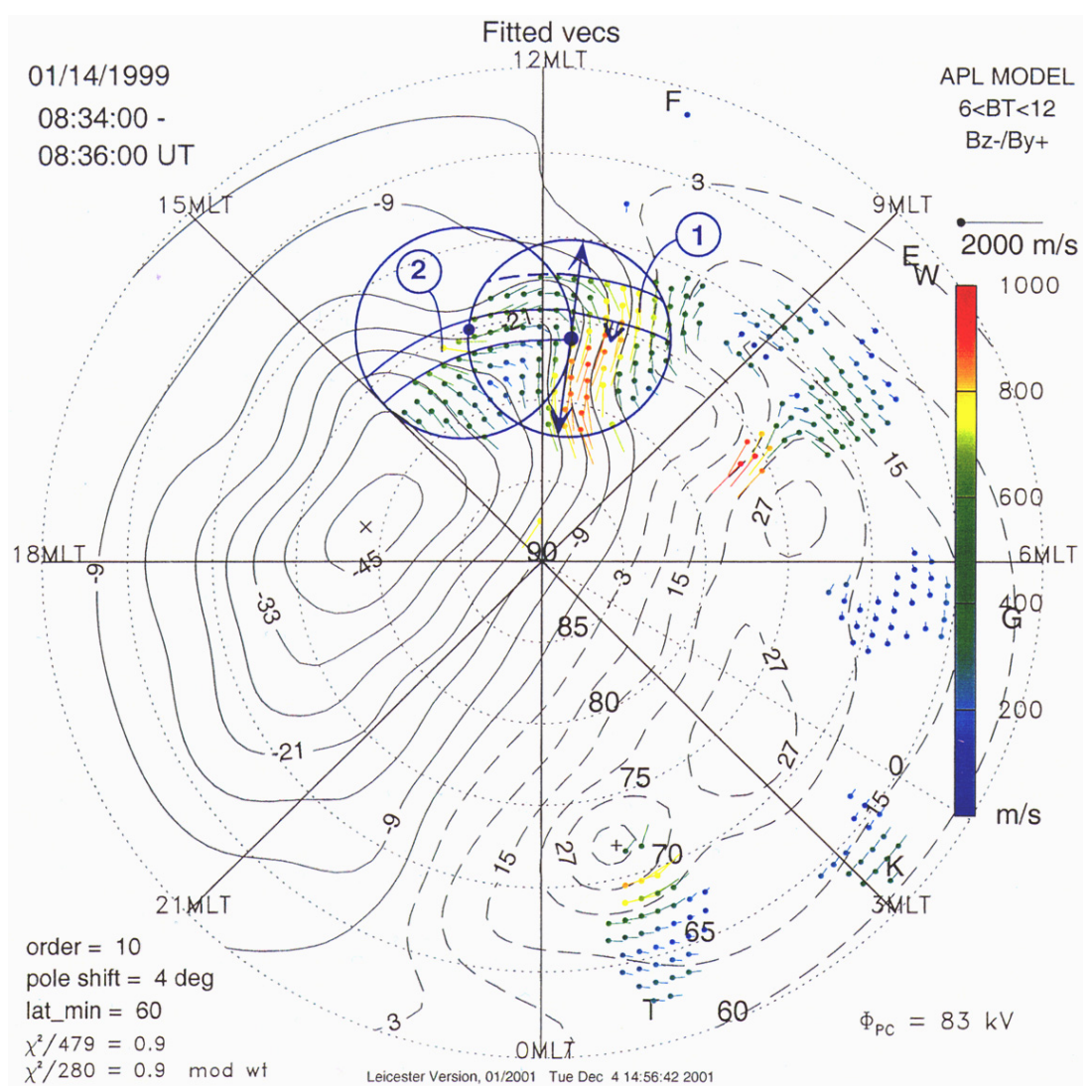

Fig. 9. SuperDARN vector plot for the center time of the main event under study (08:34-08:36 UT) in MLT/MLAT coordinates. Ion drift vectors are plotted in MLT/MLAT coordinates. Fields of view of the optical instruments in Ny Ålesund and at Heiss Island are indicated by circles and arrowed meridional line. The latter marks the FOV of the MSP in Ny Ålesund. The locations of auroral forms called types 1 and 2 are indicated.
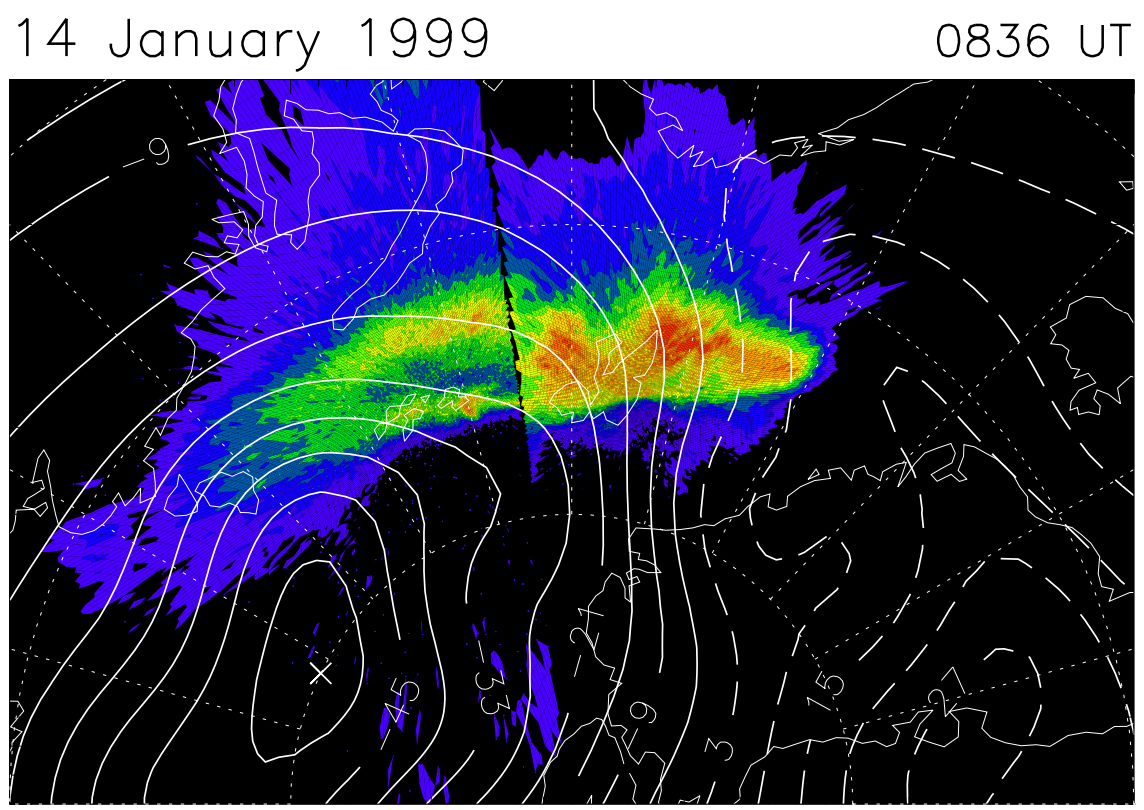

Fig. 10. SuperDARN streamline plot with the $630.0 \mathrm{~nm}$ aurora superimposed for 08:36 UT. The aurora is obtained from all-sky imagers at Heiss Island, Russia and Ny Ålesund, Svalbard. The red line emission is projected to an altitude of $250 \mathrm{~km}$. The coordinate system is MLT/MLAT. 


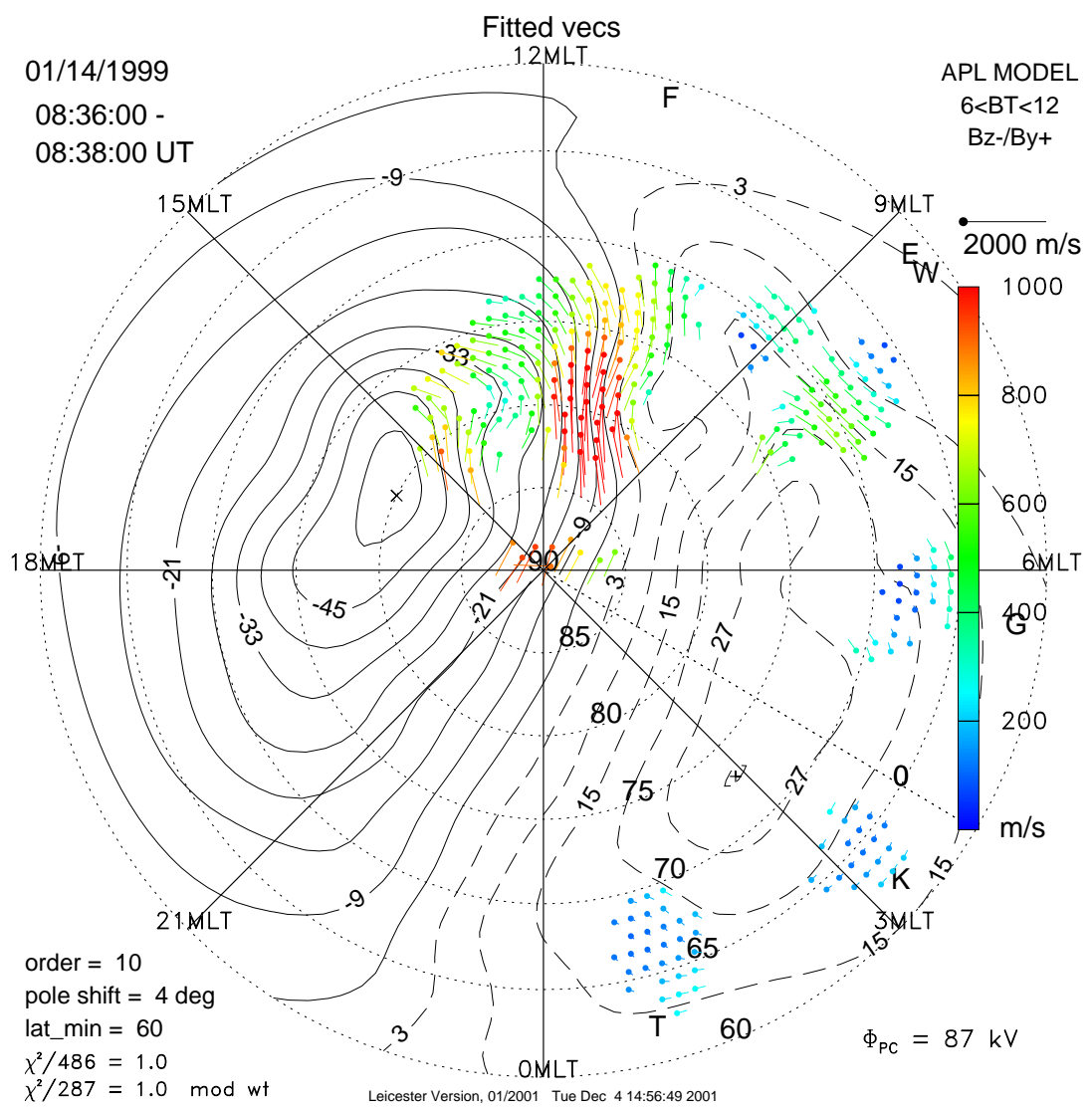

Fig. 11. SuperDARN vector plot for the interval 08:36-08:38 UT. Same format as in the previous figure.

panel 3), a channel of strong westward (antisunward) convection (panel 5), and strong magnetic deflections (bottom panel). The average energy of the electrons in the cusp is $200 \mathrm{eV}$. The magnetic deflections indicate the presence of pairs of up- and down-flowing field-aligned currents showing the same electrodynamic properties as those reported by Sandholt et al. (1989) and Lockwood et al. (2001).

A different regime of ion dispersion was observed during 08:35-08:39 UT, in the 16.9-13.5 MLT/73-75 ${ }^{\circ}$ MLAT sector. During the 08:35-08:37 UT part of this sector, the crosstrack ion drift (blue) has a clear equatorward component, in contrast to the later traversal through the stepped cusp. This is consistent with the lobe cell recorded by the SuperDARN radar (Fig. 12). The first part of the pass (08:33-08:35 UT) shows the traversal of the dusk sector of the auroral oval and its plasma sheet precipitation.

Figure 14 shows the evolution of the convection pattern (SuperDARN vector plots) for the interval 08:4608:50 UT, covering the last major "midday auroral breakup event"/PMAF in the sequence illustrated in Fig. 3. The field of view (FOV) of the meridian scanning photometer (MSP) in Ny Ålesund is marked in panels C and D. As in the previous case, the convection event starts with enhanced westward flow at the cusp equatorward boundary, accompanied by auroral brightening, during 08:44-08:46 UT. This is followed by a swing to more poleward convection (in the convection throat) and associated poleward expanding aurora in the later phase of the event (08:48-08:50 UT). The latitudinal span of the aurora at this time is marked by a bar along the MSP FOV in panel D of Fig. 14. As in the previous event, the "patch" of enhanced convection, marked by red vectors, extends to higher latitudes than the PMAF, well beyond $80^{\circ}$ MLAT. The 08:48-08:50 UT panel shows the strongest flow within $77-82^{\circ}$ MLAT, when the cusp equatorward boundary was located at $\sim 72-73^{\circ}$ MLAT.

Figure 15 shows $X$-component magnetograms from the IMAGE (International Monitor for Auroral Geomagnetic Effects) stations on Svalbard and in Scandinavia (see http://www.geo.fmi.fi/image/). The data are $10 \mathrm{~s}$ resolution. For each trace, the average over the whole interval has been subtracted from the raw readings.

The four events of type 1 auroral brightenings and associated away (antisunward/poleward) ion drift are marked by vertical full lines (event onsets) at 08:25, 08:35, 08:41, and 08:48 UT. We can see that the auroral and the radar events are accompanied by clear events of positive $X$-deflection at stations HOP-HOR-LYR-NAL, spanning the latitude range $72^{\circ}-76^{\circ}$ MLAT. This is the latitudinal band of the type 1 cusp aurora (see Fig. 2). The dash-dot line at 10:00 UT marks the abrupt recovery after the strongly negative deflection (convection bay) at cusp latitudes during the interval 


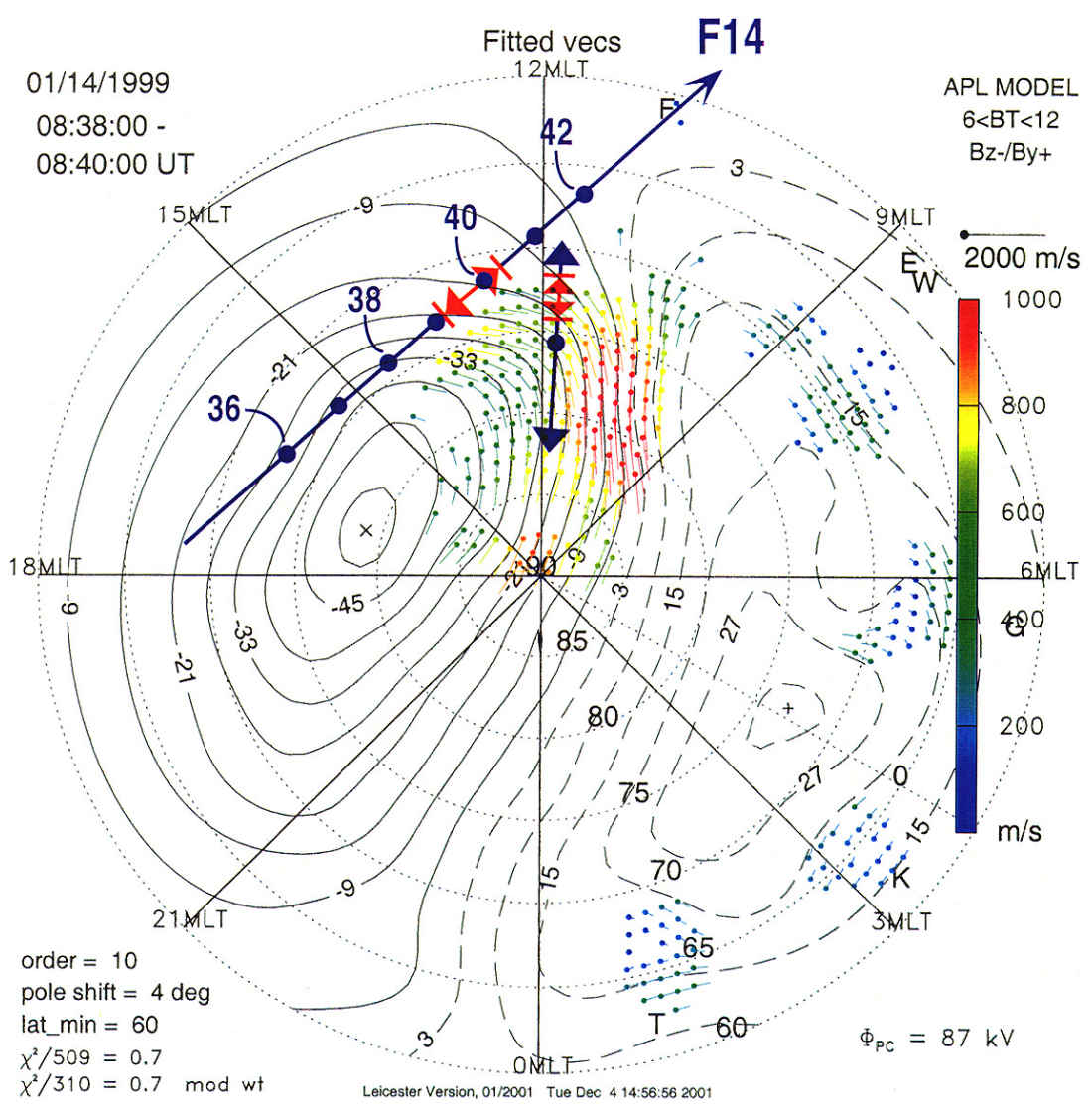

Fig. 12. SuperDARN vector plot for the interval 08:38-08:40 UT. Same format as in the previous figure. The trajectory of spacecraft DMSP F14 during the interval 08:36-08:42 UT is inserted, as well as the field of view of the MSP in Ny Ålesund (meridional double-arrowed line).

09:00-10:00 UT. This is a clear signature of the convection response to the rapid northward turning of the IMF recorded by IMP8 at 09:54 UT (see Fig. 1).

In this paper we focus on the auroral activity which ocurred during the interval 08:25-08:50 UT (associated with the four positive $X$-deflections marked by the vertical lines), before the negative convection bay during 08:55-10:00 UT. The onset of the latter convection bay was accompanied by a marked equatorward displacement of the aurora along the $\mathrm{Ny}$ Ålesund meridian to $\sim 70-72^{\circ}$ MLAT (see Fig. 4 and further comments below).

\section{Discussion}

The basis for this study is a detailed description of the 2-D structure/evolution of a sequence of auroral activations in the cusp/polar cap and the association with plasma convection observed during a $30 \mathrm{~min}$ interval on 14 January 1999 . The main features of the aurora-convection observations during two individuals events in the sequence are shown in Figs. 10 and 14 and schematically summarized in Fig. 2 . These events occurred when the interplanetary magnetic field (IMF) was relatively stable and characterized by strong $B_{y}(10 \mathrm{nT})$ and $B_{z}(-10 \mathrm{nT})$ components $\left(\right.$ clock angle $\left.\simeq 135^{\circ}\right)$. During the interval under study (08:25-08:55 UT), the cusp equa- torward boundary migrated slowly equatorward (see Fig. 3) within the latitude range $73^{\circ}-75^{\circ}$ MLAT. At the end of this interval ( $\sim 08: 55 \mathrm{UT})$, a reconfiguration occurred in aurora and plasma convection, resulting in a substantial lowering of the latitudinal position of the cusp/cleft aurora, approaching the boundary of the field of view at $\sim 70-72^{\circ}$ MLAT, and the activation of a strong magnetic convection bay at these latitudes. The latter state lasted until a strong IMF northward turning which arrived at the magnetopause just before 10:00 UT. One reason for the transition at 08:55-09:00 UT is a gradual southward rotation of the IMF from the state $\left|B_{y}\right| \geq\left|B_{z}\right|$ to the state $\left|B_{y}\right|<\left|B_{z}\right|$ (IMF clock angle increasing from below to above $135^{\circ}$ ), which was recorded by spacecraft IMP8 at $\sim 08: 40$ UT (Fig. 1 ). Related to this we note that it has been documented previously that during large, continuous southward IMF rotations, a greater qualitative change in the convection pattern occurs at $\left|B_{y}\right| \simeq\left|B_{z}\right|$ (clock angle $\simeq 135^{\circ}$ ) than at the transition through $B_{z}=0$ (Knipp et al., 1993) (see also Freeman et al., 1993; Huang et al., 2000). The corresponding change in auroral configuration at midday (meridian scanning photometer data only) and associated ground magnetic deflection, very similar to that which occurred in the present case, is seen in the two case studies reported by Sandholt and Farrugia (1999).

The events we study here belong to an interval character- 


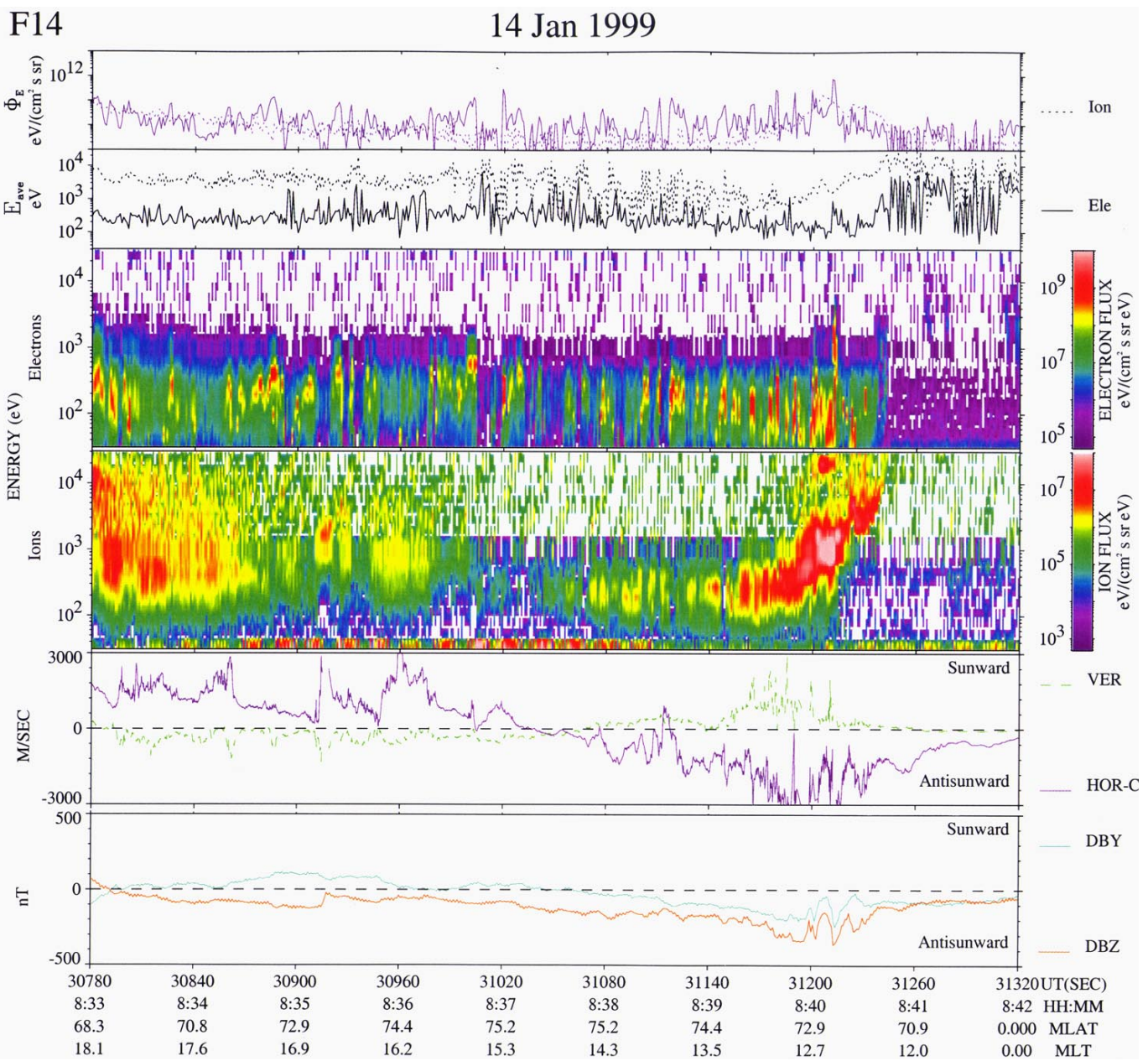

Fig. 13. Particle spectrograms, ionospheric ion drift and magnetic deflections obtained from spacecraft DMSP F14 during the interval 08:3308:42 UT on 14 January 1999. Panels 1 and 2 show differential particle flux (electrons and ions) and average energy, respectively. Panels 3 and 4 show color-coded particle spectrograms for electrons and ions, respectively. Panel 5 shows ion drift in the horizontal (cross track; violet) and vertical (upward; green) directions. Panel 6 shows the horizontal magnetic field deflection components along $\left(D B_{Y}\right)$ and normal $\left(D B_{Z}\right)$ to the satellite track.

ized by IMF $B_{y} \simeq\left|B_{z}\right|$. They appear as a sequence of brightening events which involve latitudinally and longitudinally separated cusp-type auroral forms. Individual events in the sequence consist of:

(1. initial brightening, accompanied by westward convection in the postnoon sector (12:00-15:00 MLT/ 73$75^{\circ}$ MLAT), followed by

(2. rapid westward expansion into the prenoon sector, appearing as equatorward boundary intensification/poleward expansion in the MSP records at $\mathrm{Ny}$ Ålesund, in the 10:00-12:00 MLT sector, as well as

(3. a brightening form expanding westward (towards noon) in the 12:00-15:00 MLT sector $\left(B_{y}>0\right)$, at $\sim 75-$ $77^{\circ}$ MLAT.

While the auroral phenomena (1) and (2) are accompanied by bursts of enhanced westward and poleward convection in the merging cell, the type 2 auroral events are found to be related to lobe cell convection (see also Sandholt et al., 1998a, 2001). We find that each type 2 auroral event is accompanied by a $\sim 5$-min long event of zonal (westward) convection in the postnoon sector ( 14:00-17:00 MLT), at polar cap latitudes ( $\sim 75^{\circ}$ MLAT; see Figs. 9 and 12$)$. The close association in space between the auroral forms and the composite convection pattern, consisting of merging and lobe cells, during a long sequence of auroral events, was indicated in Sandholt et al. (2001). However, in that case the optical field of view was limited to a single meridian (the Ny Ålesund MSP meridian). In this case we demonstrated the detailed temporal-spatial evolution of the auroral forms by applying observations from two all-sky cameras with partly overlapping fields of view. This extended instrumentation was particularly appropriate for demonstrating the evolution of the type 1 and 2 auroral events. Furthermore, in the present case the FOV of the Cutlass Finland radar (see Fig. 2) was ideally located for monitoring the temporal evolution of the convec- 


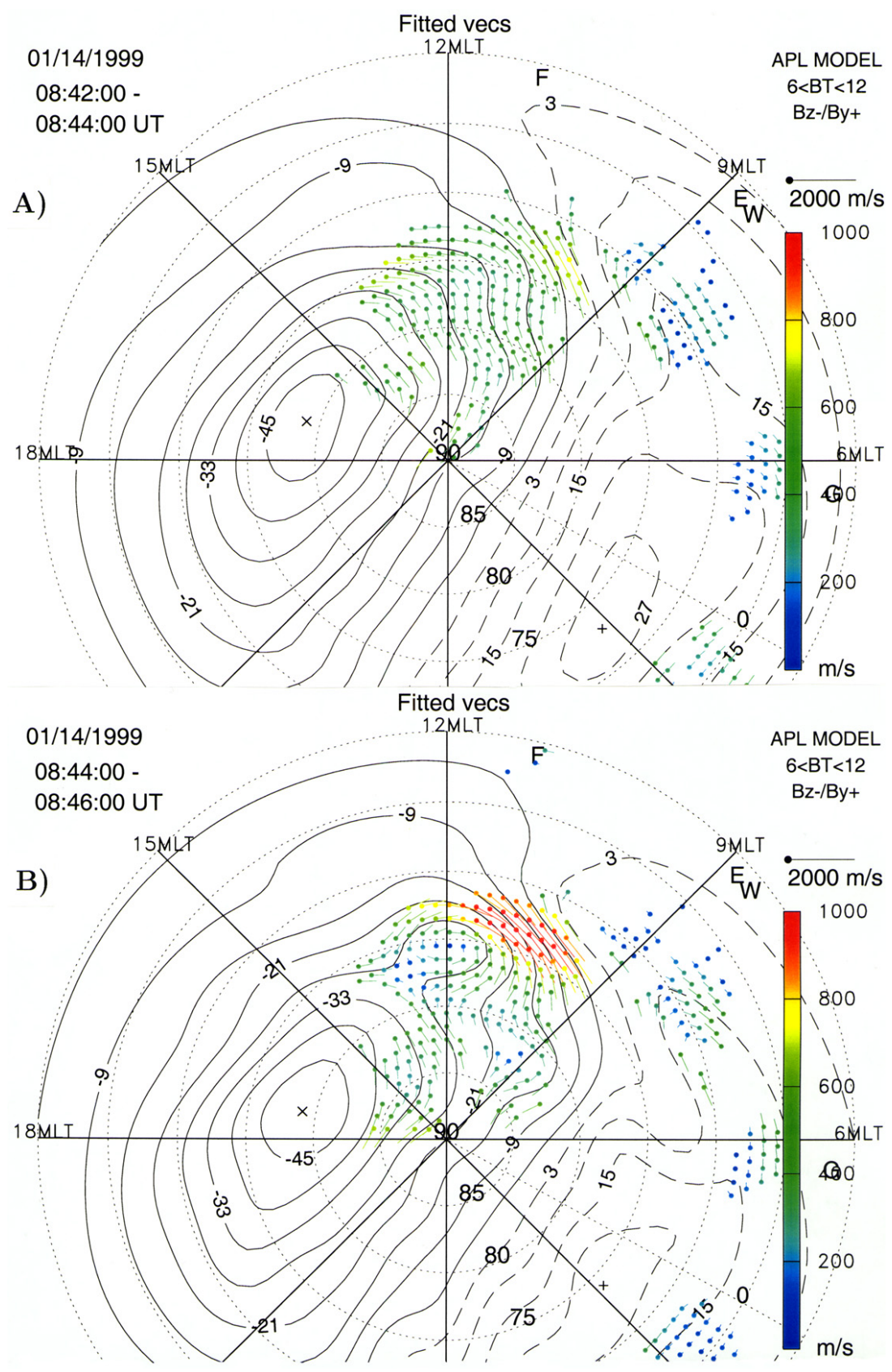

Fig. 14. Panels A, B, C, and D show SuperDARN vector plots for the intervals 08:42-08:44, 08:44-08:46, 08:46-08:48, and 08:48-08:50 UT, respectively. Same format as in the previous figure. The MSP field of view and the approximate latitudinal extent of the aurora are marked by double-arrowed meridional line and bars, respectively, in panels C and D (Fig. 14 continues).

tion pattern on the dayside.

The main thrust of this paper is, therefore, the demonstration of the 2-D morphology and dynamics of the interrelated activations of latitudinally and longitudinally separated auroral forms in the cusp/polar cap, and the association with a composite pattern of merging and lobe convection cells (Reiff and Burch, 1985). Combining the present results with those reported in Sandholt et al. (2001), we find that this auroral configuration/convection pattern is typical for intervals of $B_{y}$-dominant IMF orientation (including the clock angle range $90^{\circ}-135^{\circ}$ ). The aurora in this case may correspond to the type of double (or bifurcated) cusp precipitation that has been reported by Wing et al. (2001). The association between aurora and particle precipitation (protons and electrons) for such cases has been documented in a recent study by Sandholt et al. (2002).

We note that the type 1 auroral brightenings recorded by the meridian scanning photometer in Ny Ålesund are located in the convection throat in the prenoon sector (marked by cross-hatching in Fig. 2) during the prevailing $B_{y}>0$ and $B_{x}<0$ conditions, which is in agreement with the results of Maynard et al. (2001) (concerning the plasma con- 


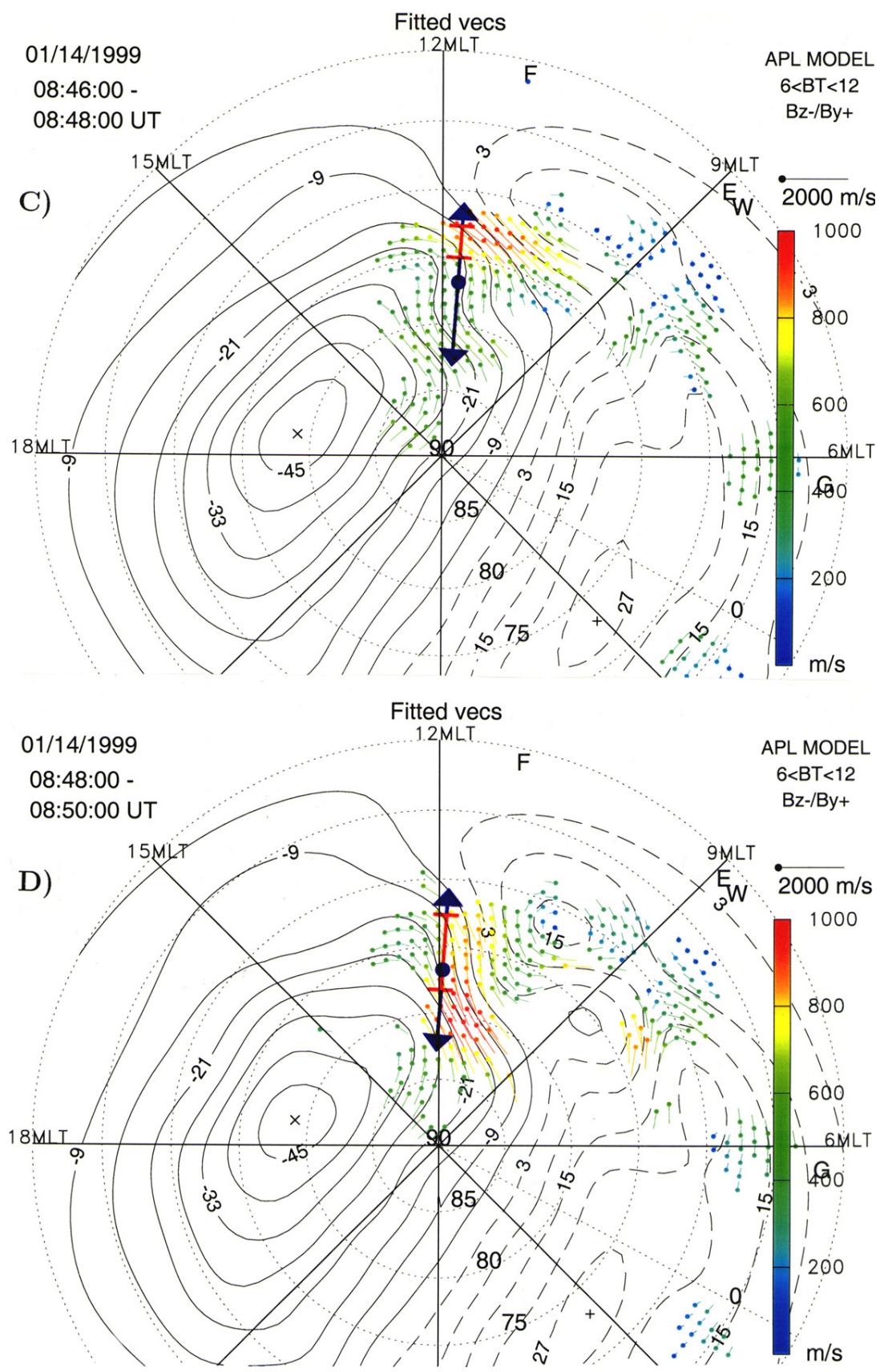

Fig. 14. ... continued.

figuration, see also Neudegg et al., 2001, and the pulsed ionospheric flows (PIFs) statistics of Provan et al., 1999). The auroral transition appearing in the MSP records at 09:00 UT/12:00 MLT (Fig. 4), when the PMAF sequence is replaced by an aurora at lower latitude, took place when the Ny Ålesund MSP moved out of the convection throat (with poleward convection), into the postnoon sector, where the local convection is more zonal (westward return flow in the postnoon sector) (see Fig. 9). Here it is also shown that the type 1 auroral activations (near the cusp equatorward boundary) and subsequent poleward expansions (PMAFs) are accompanied by episodes of enhanced westward flow followed by swings to antisunward (poleward) drift in the convection throat (Figs. 7, 9, 11 and 14) and $X$-component magnetic deflection (Fig. 15) at cusp latitudes. The convection enhancements evolve with time towards higher latitudes in the cusp/mantle region (Figs. 9, 11 and 14). The latter is in agreement with previous radar observations of enhanced poleward flow poleward of the cusp, which has been attributed to a transient increase in dayside reconnection (Greenwald et al., 1999). The pulsed nature of the type 1 cusp aurora is clearly demonstrated in Fig. 3. We have documented the one-to-one association between the auroral and convection events.

One important feature in the data set deserves further comment, that is the bursts of westward convection appearing as 


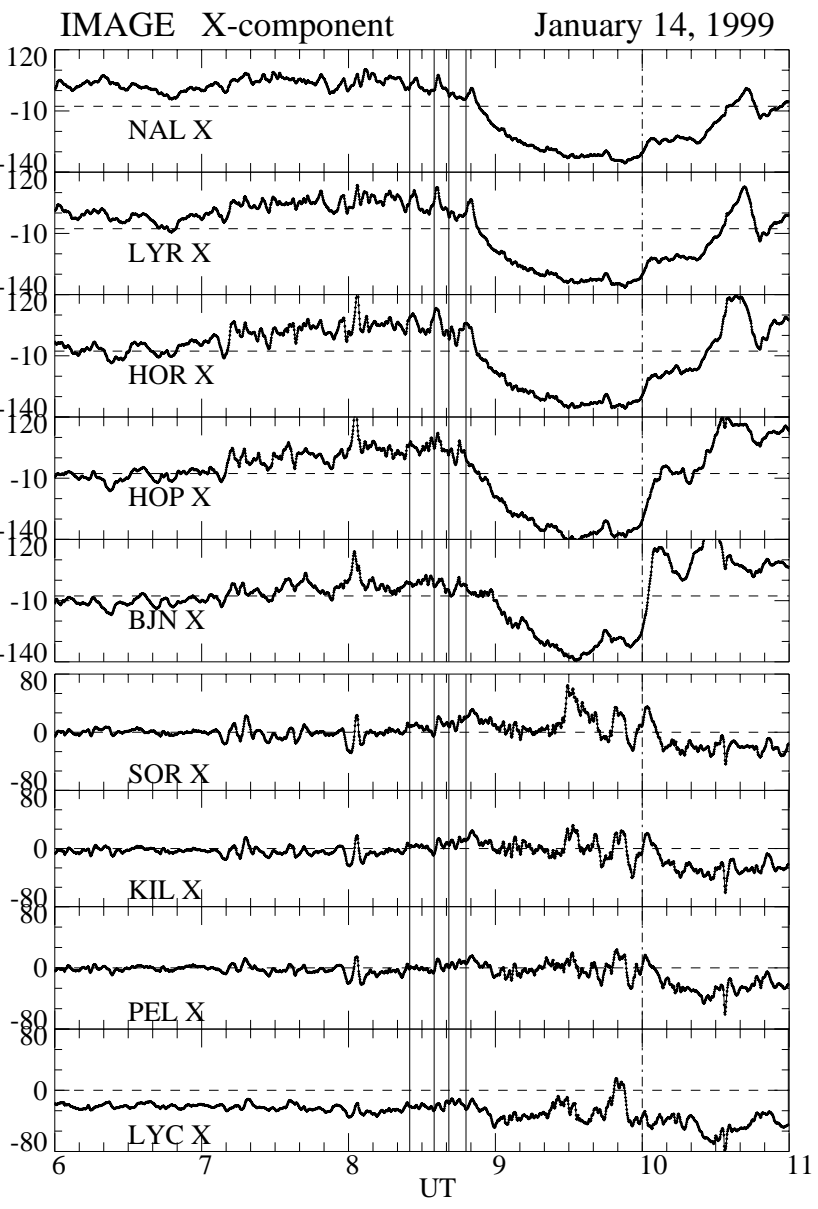

Fig. 15. Magnetometer data from the IMAGE chain of magnetometers in Svalbard and Scandinavia. Panels from top to bottom show X-component traces from stations Ny Ålesund (NAL; $76.1^{\circ} \mathrm{MLAT}$; optical site), Longyearbyen (LYR; 75. $1^{\circ}$ MLAT), Hornsund (HOR; 74.0 $0^{\circ}$ MLAT), Hopen (HOP; $72.9^{\circ}$ MLAT), Bear Island (BJN; $71.3^{\circ}$ MLAT), Sørøya (SOR; 67.3 MLAT), Kilpisjærvi (KIL; 65.9 ${ }^{\circ}$ MLAT), Pello (PEL; 63. $6^{\circ}$ MLAT), and Lycksele (LYC; $61.4^{\circ}$ MLAT).

a toward flow (blue) in beam 14 of the CUTLASS radar in the 12:00-14:00 MLT/ 73-75 MLAT sector in the early phase of the events described above. We note that the flow is not always strictly westward, e.g. an equatorward component may be present at times (see also Neudegg et al., 2001). However, the occasional presence of an equatorward flow component could be an artifact. Clear examples are represented by the intervals 08:32-08:34 UT (see Figs. 7 and 8) and 08:4408:46 UT (Fig. 14). The aurora corresponding to the former event is seen in the lower section of the Heiss Island images in Fig. 6. The phenomenon also appears to be present in the form of initial brightenings seen in the MSP plot in Fig. 3 during the intervals 08:32-08:34 and 08:44-08:46 UT. Referring back to the schematical illustation in Fig. 2, this aurora-convection feature in our data set is manifest in the region of the single-hatched region south of $75^{\circ}$ MLAT in the $\sim$ 12:00-14:00 MLT sector and along the most equatorward bar marked along antenna beam 14. In our view this phenomenon is well explained by the model of the initial ionospheric flow response to flux transfer events during $B_{y}>0$ conditions, as illustrated schematically in Fig. 4 of Milan et al. (2000) (see also Cowley, 1998).

The evolution of the present aurora-convection events may be explained in terms of a wave-like propagation of reconnection events on the dayside magnetopause, much in the way as was explained in recent studies by Milan et al. (2000) and Sandholt et al. (2001). The upper panel of Fig. 16 shows a tilted reconnection line on the magnetopause for IMF $B_{y}>0$ conditions (IMF clock angle $\sim 135^{\circ}$ ) and field lines just inside the magnetopause which are tilted over in the direction of IMF $B_{y}$ (see Cowley et al., 1991). The northern cusp, displaced into the post-noon sector, is thus connected with the southern cusp which is displaced pre-noon. This is the sense of displacement of the main cusp as determined by Newell et al. (1989) from DMSP particle precipitation data. A burst of magnetopause reconnection starting at noon (component reconnection in the subsolar region) will first map into the post-noon sector in the Northern Hemisphere, followed by propagation away from this centre both west and east, towards higher latitudes. In the ionosphere the westward (dawnward) propagation/expansion at the magnetopause (in the Southern Hemisphere) results in an auroral transient propagating at lower latitudes around noon from post-noon to pre-noon at the equatorward edge of the merging cell. The eastward (duskward) propagation to higher latitudes at the magnetopause eventually produces the type 2 auroral form, which will also propagate westward towards noon in the lobe cell due to field tension (curvature force). This evolution of the ionospheric events is indicated in the lower panel of Fig. 16. The two open arrows mark westward surges of the type 1 and 2 auroras. Thus, our interpretation of the auroral data is that the reconnection signature starts in the ionosphere post-noon (due to field line tilting), and then propagates in both directions, east to give the type 2 aurora eventually, and west to give the westward propagation across noon of the type 1 aurora. The latter auroral expansion from post-noon to pre-noon, which is often observed (see e.g. Sandholt et al., 1998c, their Plate 2), is in our view in good agreement with the presence of a tilted X-line in the subsolar region, which is based on the component reconnection model (see Introduction).

Related to the above interpretation we note that a combined ground-satellite data study of plasma convection and particle precipitation during similar IMF conditions, as in the present case, has been reported by Coleman et al. (2001). Their data set was found to be consistent with antiparallel, steady state merging, as described by Crooker (1979) and Luhmann et al. (1984). That interpretation is based on the observation of certain convection vortices involving strong equatorward flow at cusp latitudes at noon, and an ion dispersion signature consistent with steady-state reconnection. In their view, the cusp is spatially bifurcated due to 2 spatially separated reconnection sites on the magnetopause. We find that the auroral evolution (activation sequence) reported 


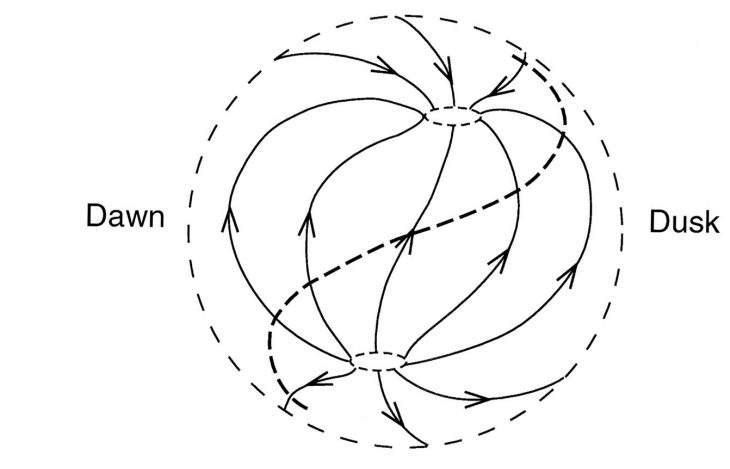

----- Reconnection line

tor, which is in very good agreement with the observation in our case, as well as the previously reported observations. We point out the association between classical PMAFs, for example, those emanating from cusp equatorward boundary intensifications (EBIs) and fading out $\sim 500 \mathrm{~km}$ further north, and the poleward ion flow in the convection throat. Thus, we conclude that these poleward moving/expanding forms (Fig. 3) represent a low-altitude signature of the evolution of plasma transfer/precipitation along reconnected field lines in the cusp/mantle regime/convection throat during $\sim 5-10$ min long intervals following the initial EBIs. The "patch" of enhanced $(\sim 1 \mathrm{~km} / \mathrm{s})$ poleward convection, observed within a latitude range, located $\sim 500-1000 \mathrm{~km}$ poleward of the cusp equatorward boundary in the late phase of the PMAFs, is then related to the addition of new open flux to the highlatitude boundary layer (mantle/lobe), as described by Cowley and Lockwood (1992), and the associated solar windmagnetosphere dynamo action $(\boldsymbol{j} \cdot \boldsymbol{E}<0)$ taking place there (Siscoe et al., 1991). It has been previously documented that the fading phase of PMAFs occurs within the regime of mantle precipitation (Sandholt et al., 1993). Steady-state aspects of the high-latitude dynamo process for the actual IMF orientation (IMF $B_{y}>0$ ) are discussed by, for example, Taguchi et al. (1993). Our aurora-convection results are in good agreement with the recent study of Provan et al. (2002), showing that the high-latitude pulsed ionospheric flows are observed within the regime of mantle precipitation and can be considered as "fossilized signatures of dayside reconnection, observed as the field lines are being pulled antisunward by the magnetosheath flow."

From the reported observations we may consider the parin the direction of IMF $B$. Reconnection line is marked by dashed tilted line. North is up and the dawn side is to the left. The lower panel shows the corresponding convection pattern with cusp auroral precipitations. 12:00 MLT is up and the dusk side is to the left. Open arrows mark the westward expansions of the two components of the bifurcated cusp aurora associated with activations of merging and lobe convection cells. The ionospheric footprint of the merging line is marked by dashed curved line. The dotted line marks the open-closed field line boundary.

here, characterized by rapid auroral expansion across noon, as described above, is consistent with the presence of component reconnection in the subsolar region. This scenario is also supported by the ionospheric ion flow at noon, which is mainly westward, and definitely turns northwestward in the later phase of each event. Furthermore, the clearly stepped (or staircase) cusp, in combination with the optical data (a clear sequence of brightening/expansion events), lead us to interpret our observations in terms of a bursty reconnection process. We note, however, that in order to completely resolve the component versus antiparallel reconnection issue, we need to examine more examples.

In the configuration indicated in Fig. 16, characteristic of IMF $B_{y}>0$ conditions, poleward moving auroral forms (PMAFs) are expected to occur in the region where the merging cell flow turns poleward in the $\sim 10$ :00-12:00 MLT sectitioning of the total polar cap potential drop $\left(\Phi_{P C}=\right.$ $80-90 \mathrm{kV}$ ) among the merging and lobe convection cells, in line with the discussion in Crooker et al. (1998). In the case discussed by Crooker et al. (1998), for an IMF pointing due west (clock angle $=90^{\circ}$ ), the merging and lobe cells contributed 65 and $25 \mathrm{kV}$, respectively. In the present case we estimate from the potential contour plots in Figs. 9 and 11 that the merging and lobe cells contributed $\sim 60$ and $20 \mathrm{kV}$, respectively. This is based on the following estimate of the location of the equatorward boundary of the lobe cell. The DMSP F14 pass (Fig. 12) is skimming this lobe cell boundary at $\sim 75^{\circ}$ MLAT in the 14:00-17:00 MLT sector during the interval 08:35-08:38 UT. This sector is characterized by southwestward (sunward) ionospheric ion flow and particle precipitation typical of the lobe cell (Eriksson et al., 2002). In the DMSP F14 data (Fig. 13) the latter precipitation is located between a zone of plasma sheet precipitation (before 08:35 UT) and a cusp-mantle region with standard ion dispersion (08:38:00-08:40:30 UT).

We note that many of the apparent "rebrightenings" at high latitudes of poleward moving auroral forms (PMAFs) in meridian scanning photometer (MSP) records (Sandholt et al., 1986; Fasel, 1995) may be due to type 2 auroral forms expanding into the MSP field of view from the side, as exemplified by the 08:35 UT case in the present study. Other, more spectacular examples of such "rebrightening" events, which 
occurred during similar IMF conditions, as in the present case (or slightly lower clock angles), are seen in Plates 1 and 2 in Sandholt et al. (1998a, c, 2001) (see also Øieroset et al., 1997). An interesting observation to note, which is in accordance with the present interpretation, is that these "rebrightenings"/bifurcations disappeared when the IMF clock angle increased above $\sim 135^{\circ}$. So, the disappearance of the PMAF/"rebrightening" phenomenon in the MSP records at 09:00 UT/12:00 MLT in the present case may be due to a combination of two effects, one being a spatial and the other a temporal structure: (i) the MSP moved out of the convection throat, and (ii) the IMF rotated further south (beyond $135^{\circ}$ clock angle), giving rise to a reconfiguration of the convection pattern, which approached a more symmetrical two-cell configuration (see Huang et al., 2000). If we then briefly return to the auroral condition at 08:00-08:15 UT (Fig. 3), when IMF $B_{z}$ was close to zero (clock angle $\sim 90^{\circ}$ ), the highest-latitude form represents the type 2 aurora and the lobe cell when its focus was located closer to midday and at higher latitude, in agreement with the results of Huang et al. (2000).

Finally, we point out that the rather broad energy spectrum $(\sim 30-600 \mathrm{eV}$; occasionally reaching above $1 \mathrm{keV})$ of the highly structured electron precipitation (latitudinally separated current filaments) permeating the cusp region (see Fig. 13) is consistent with the presence of long auroral rays, spanning much of the altitude range $\sim 120-400 \mathrm{~km}$, which is so characteristic for this locale.

Acknowledgements. We thank Bjørn Lybekk and Espen Trondsen for technical assistance during the collection and with the presentation of the optical data. The IMAGE magnetometer data used in this paper were collected as a German-Finnish-Polish-Norwegian project conducted by the Technical University of Braunschweig and the Finnish Meteorological Institute. The auroral observation program on Svalbard is supported by the Norwegian Research Council, AFOSR Task 2311AS, and the Norwegian Polar Research Institute. The CUTLASS radar is funded by the Particle Physics and Astronomy Research Council on grant PPA/R/R/1997/00256. SWHC and SEM are supported by PPARC Senior Fellowship PPA/N/S/2000/00197. CJF is supported by NASA grant NAG 5-2834 and NASA Living with a Star Grant Nag 5-10883.

Topical Editor G. Chanteur thanks G. Chisham and another referee for their help in evaluating this paper.

\section{References}

Coleman, I. J., Chisham, G., Pinnock, M., and Freeman, M. P.: An ionospheric convection signature of antiparallel reconnection, J. Geophys. Res., 106, 28 995, 2001.

Cowley, S. W. H.: Magnetospheric asymmetries associated with the Y-component of the IMF, Planet. Space Sci., 29, 79-, 1981.

Cowley, S. W. H.: Solar wind control of magnetospheric convection, in: Achievements of the International Magnetospheric Study (IMS), no. SP-217 in ESA Special Publ., ESA (European Space Agency), Noordwijk, The Netherlands, 483-494, 1984.

Cowley, S. W. H.: Excitation of flow in the Earth's magnetosphereionosphere system: Observations by incoherent-scatter radar, in: Polar Cap Boundary Phenomena, (Eds) Moen, J., Egeland, A., and Lockwood, M., vol. 509 of NATO ASI Series C, Kluwer Academic Publishers, Dordrecht, Holland, 127-140, 1998.

Cowley, S. W. H. and Lockwood, M.: Excitation and decay of solar wind-driven flows in the magnetosphere-ionosphere system, Ann. Geophysicae, 10, 103, 1992.

Cowley, S. W.H., Morelli, J. P., and Lockwood, M.: Dependence of convective flows and particle precipitation in the high-latitude dayside ionosphere on the $X$ and $Y$ components of the interplanetary magnetic field, J. Geophys. Res., 96, 5557, 1991.

Crooker, N. U., Lyon, J. G., and Fedder, J. A.: MHD model merging with IMF $B_{y}$ : Lobe cells, sunward polar cap convection, and overdraped lobes, J. Geophys. Res., 103, 9143, 1998.

Crooker, N. U.: Dayside merging and cusp geometry, J. Geophys. Res., 84, 951, 1979.

Eriksson, S., Bonnell, J. W., Blomberg, L. G., Ergun, R. E., Marklund, G. T., and Carlson, C. W.: Lobe cell convection and fieldaligned currents poleward of the Region 1 current system, J. Geophys. Res., 107(A8)10.10029/2001JA005041, 2002.

Escoubet, C. P., Smith, M. F., Fung, S. F., Anderson, P. C., Hoffman, R. A., Basinska, E. M., and Bosqued, J. M.: Staircase ion signature in the polar cusp: A case study, Geophys. Res. Lett., 19, 1735, 1992.

Farrugia, C. J., Sandholt, P. E., Denig, W. F., and Torbert, R. B.: Observation of a correspondence between poleward-moving auroral forms and stepped cusp ion precipitation, J. Geophys. Res., 103, 9309, 1998.

Fasel, G.: Dayside poleward moving auroral forms: A statistical study, J. Geophys. Res., 100, 11 891, 1995.

Freeman, M. P., Farrugia, C. J., Burlaga, L. F., Hairston, M. R., Greenspan, M. E., Ruohoniemi, J. M., and Lepping, R. P.: The interaction of a magnetic cloud with the Earth: Ionospheric convection in the northern and southern hemispheres for a wide range of quasi-steady interplanetary magnetic field conditions, J. Geophys. Res., 98, 7633-7655, 1993.

Gonzalez, W. D. and Mozer, F.: A quantitative model for the potential resulting from reconnection with an arbitrary interplanetary magnetic field, J. Geophys. Res., 79, 4186, 1974.

Greenwald, R. A., Baker, K., Dudeney, J. R., Pinnock, M., Thomas, E. C., Villain, J. P., Cerisier, J.-C., Senior, C., Hanuise, C., Hunsucker, R. D., Sofko, G. J., Koehler, J., Nielsen, E., Pellinen, R., Walker, A.D.M., Sato, N., and Yamagishi, H.: DARN/SUPERDARN, Space Sci. Rev., 71, 761, 1995.

Greenwald, R. A., Ruohoniemi, J. M., Baker, K., Bristow, W. A., Sofko, G. J., Villain, J. P., Lester, M., and Slavin, J.: Convective response to a transient increase in dayside reconnection, J. Geophys. Res., 104, $10007,1999$.

Huang, C.-S., Murr, D., Sofko, G. J., Hughes, W. J., and Moretto, T.: Ionospheric convection response to changes of interplanetary magnetic field $B_{z}$ component during strong $B_{y}$ component, J. Geophys. Res., 105, 5231, 2000.

Kawano, H. and Russell, C.: Survey of flux transfer events observed with the ISEE 1 spacecraft: Dependence on the interplanetary magnetic field, J. Geophys. Res., 102, 11 307, 1997.

Knipp, D. J., Emery, B. A., Richmond, A. D., Crooker, N., Hairston, M. R., Cumnonck, J. A., Denig, W. F., Rich, F. J., de la Beaujardiere, O., Ruohoniemi, J. M., Rodger, A. S., Crowley, G., Ahn, B.-H., Evans, D. S. Fuller-Rowell, T. J., Friis-Christensen, E., Lockwood, M., Kroehl, H. W., Maclennan, C. G., Mc Ewin, A., Troshichev, O., Sato, N., Sutcliffe, P., and Tomlinson, L.: Ionospheric convection response to slow, strong variations in a northward interplanetary magnetic field: A case study for January 14, 1988, J. Geophys. Res., 98, 19273, 1993. 
Lockwood, M., Sandholt, P. E., Cowley, S. W.H., and Oguti, T.: Interplanetary magnetic field control of dayside auroral activity and the transfer of momentum across the dayside magnetopause, Planet. Space Sci., 37, 1347, 1989.

Lockwood, M., Milan, S. E., Onsager, T., Perry, C. H., Scudder, J. A., Russell, C. T., and Brittnacher, M.: Cusp ion steps, fieldaligned currents and poleward moving auroral forms, J. Geophys. Res., 106, 29 555, 2001.

Lu, G., Richmond, A., Emery, B., Reiff, P., de la Beaujardiére, O., Rich, F., Denig, W., Kroehl, H., Lyons, L., Ruohniemi, J., Friis-Christensen, E., Opgenoorth, H., Persson, M., Lepping, R., Rodger, A., Hughes, T., McEwin, A., Dennis, S., Morris, R., Burns, G., and Tomlinson, L.: Interhemispheric asymmetry of the high-latitude ionospheric convection pattern, J. Geophys. Res., 99, 6491-6510, 1994.

Luhmann, J. G., Walker, R. J., Russell, C. T., Crooker, N. U., Spreiter, J. R., and Stahara, S. S.: Patterns of potential magnetic field merging sites on the dayside magnetopause, J. Geophys. Res., 89, 1739, 1984.

Marcucci, M. F., Cattaneo Bavassano, M. B., Di Lellis, A. M., Cerulli, Irelli, P., Kistler, L. M., Phan, T.-D., G., H., Klecker, B., Paschmann, G., Baumjohann, W., Mobius, E., Popecki, M. A., Sauvaud, J. A., Reme, H., Korth, A., Eliassen, L., Carlsson, C. W., McCarthy, M., and Parks, G. K.: Evidence for interplanetary magnetic field $B_{y}$ controlled large-scale reconnection at the dayside magnetopause, J. Geophys. Res., 105, 27 497, 2000.

Maynard, N. C., Burke, W. J., Sandholt, P. E., Moen, J., Ober, D. M., Lester, M., Weimer, D. R., and Egeland, A.: Observations of simultaneous effects of merging in both hemispheres, J. Geophys. Res., 106, 24 551, 2001.

Milan, S., Lester, M., Cowley, S. W. H., and Brittnacher, M.: Convection and auroral response to a southward turning of the IMF: Polar UVI, CUTLASS and IMAGE signatures of transient flux transfer at the magnetopause, J. Geophys. Res., 105, 15741, 2000.

Moen, J., van Eyken, A. P., and Carlson, H. C.: EISCAT Svalbard Radar observations of ionospheric plasma dynamics in relation to dayside auroral transients, J. Geophys. Res., 106, 21 453, 2001.

Neudegg, D. A., Cowley, S. W. H., McWilliams, K. A., Lester, M., Yeoman, T. K., Sigwarth, J., Haerendel, G., Baumjohann, W., Auster, U., Fornaçon, K.-H., and Georgescu, E.: The UV aurora and ionospheric flows during flux transfer events, Ann. Geophysicae, 19, 179, 2001.

Newell, P. T., Meng, C.-I., Sibeck, D., and Lepping, R.: Some lowaltitude cusp dependencies on the interplanetary magnetic field, J. Geophys. Res., 94, 8921, 1989.

Øieroset, M., Sandholt, P. E., Luhr, H., Denig, W., and Moretto, T.: Auroral and geomagnetic events at cusp/mantle latitudes in the prenoon sector during positive IMF $B_{y}$ conditions: Signatures of pulsed magnetopause reconnection, J. Geophys. Res., 102, 7191, 1997.

Popescu, D., Sauvaud, J.-A., Fedorov, A., Budnik, E., Stenuit, H., and Moreau, T.: Evidence for a sunward flowing plasma layer adjacent to the tail high-latitude magnetopause during dawnward directed interplanetary field, J. Geophys. Res., 106, 29 479, 2001.

Provan, G., Yeoman, T. K., and Cowley, S. W. H.: The influence of the IMF $B y$ component on the location of pulsed flows in the dayside ionosphere observed by an HF radar, Geophys. Res. Lett., 26, 521, 1999.

Provan, G., Milan, S. E., Lester, M., Yeoman, T. K., and Khan, H.: Simultaneous observations of the ionospheric footprint of flux transfer events and dispersed ion signatures, Ann. Geophysicae,
20, 281, 2002.

Reiff, P. H. and Burch, J. L.: IMF $\mathrm{B}_{y}$-dependent dayside plasma flow and Birkeland currents in the dayside magnetosphere, 2, A global model for northward and southward IMF, J. Geophys. Res., 90, 1 595, 1985.

Rodger, A. S., Coleman, I. J., and Pinnock, M.: Some comments on transient and steady-state reconnection at the dayside magnetopause, Geophys. Res. Lett., 27, 1359, 2000.

Ruohoniemi, J. M. and Baker, K. B., Large-scale imaging of highlatitude convection with Super Dual Auroral Radar Network HF radar observations, J. Geophys. Res., 103, $20797,1998$.

Russell, C. T. and Elphic, R. C.: Initial ISEE magnetometer results: Magnetopause observations, Space Sci. Rev., 22, 681, 1978.

Sandholt, P. E. and Farrugia, C. J.: On the dynamic cusp aurora and IMF $B_{y}$, J. Geophys. Res., 104, 12 461, 1999.

Sandholt, P. E., Deehr, C. S., Egeland, A., Lybekk, B., Viereck, R., and Romick, G. J.: Signatures in the dayside aurora of plasma transfer from the magnetosheath, J. Geophys. Res., 91, 10063 , 1986.

Sandholt, P. E., Jacobsen, B., Lybekk, B., Egeland, A., Bythrow, P. F., and Hardy, D. A.: Electrodynamics of the polar cusp ionosphere: A case study, J. Geophys. Res., 94, 6713, 1989.

Sandholt, P. E., Moen, J., Rudland, A., Opsvik, D., Denig, W. F., and Hansen, T.: Auroral event sequences at the dayside polar cap boundary for positive and negative interplanetary magnetic field $B_{y}$, J. Geophys. Res., 98, 7737, 1993.

Sandholt, P. E., Farrugia, C. J., and Cowley, S. W. H.: Pulsating cusp aurora for northward IMF, J. Geophys. Res., 103, 26 507, 1998a.

Sandholt, P. E., Farrugia, C. J., Moen, J., and Cowley, S. W. H.: Dayside auroral configurations: Responses to southward and northward rotations of the interplanetary magnetic field, J. Geophys. Res., 103, 20279 , 1998b.

Sandholt, P. E., Farrugia, C. J., Moen, J., Cowley, S. W.H., and Lybekk, B.: Dynamics of the aurora and associated convection currents during a cusp bifurcation event, Geophys. Res. Lett., 25, 4313, 1998c.

Sandholt, P. E., Farrugia, C. J., Cowley, S. W. H., and Lester, M.: Dayside auroral bifurcation sequence during $B_{y}$-dominated interplanetary magnetic field: Relationship with merging and lobe convection cells, J. Geophys. Res., 106, 15 429, 2001.

Sandholt, P. E., Denig, W. F., Farrugia, C. J., Lybekk, B., and Trondsen, E.: Auroral structure at the cusp equatorward boundary: Relationship with the electron edge of low-latitude boundary layer precipitation, J. Geophys. Res., 107(A9)10.1029/2001JA005081, 2002.

Siscoe, G. L., Lotko, W., and Sonnerup, B. U. O.: A high-latitude, low-latitude boundary layer model of the convection current system, J. Geophys. Res., 96, 3487, 1991.

Siscoe, G. L., Erickson, G. M., Sonnerup, B. U. O., Maynard, N. C., Siebert, K. D., Weimer, D. R., and White, W. W.: Global role of $E_{\|}$in magnetopause reconnection: An explicit demonstration, J. Geophys. Res., 106, 13 015, 2001.

Sonnerup, B. U. O.: Magnetic field line reconnection at the magnetopause: An overview, in: Magnetic reconnection in Space and Laboratory Plasmas, (Ed) Hones, E. W., vol. 30 of Geophysical Monograph, 92-103, AGU, Washington, D.C., 1984.

Taguchi, S., Sugiura, M., Winningham, J. D., and Slavin, J.: Characterization of the IMF $B y$-dependent field-aligned currents in the cleft region based on DE 2 observations, J. Geophys. Res., 98, 1393, 1993.

Weimer, D. R.: Maps of ionospheric field-aligned currents as a function of the interplanetary magnetic field derived from Dy- 
namics Explorer 2 data, J. Geophys. Res., 106, 12 889, 2001.

Weiss, L. A., Reiff, P. H., Weber, E. J., Carlson, H. C., Lockwood, M., and Peterson, W. K.: Flow-aligned jets in the magnetospheric cusp: Results from the geospace environment modeling pilot program, J. Geophys. Res., 100, 7 649, 1995.

White, W., Siscoe, G. L., Erickson, G. M., Kaymaz, Z., Maynard, N. C., Siebert, K. D., Sonnerup, B. U. O., and Weimer, D. R.: The magnetospheric sash and the cross-tail s, Geophys. Res.
Lett., 25, 1605, 1998.

Wing, S., Newell, P. T., and Ruohoniemi, J. M.: Double cusp: Model prediction and observational verification, J. Geophys. Res., 106, 25 571, 2001.

Yeoman, T. K., Lester, M., Cowley, S. W. H., Milan, S. E., Moen, J., and Sandholt, P. E.: Simultaneous observations of the cusp in optical, DMSP and HF radar data, Geophys. Res. Lett., 24, 2251, 1997. 